\title{
The added value of a regional landslide susceptibility assessment: the western branch of the East African Rift
}

Arthur Depicker ${ }^{\mathrm{a}}$, Liesbet Jacobs ${ }^{\mathrm{a}}$, Damien Delvaux ${ }^{\mathrm{b}}$, Hans-Balder Havenith $^{\mathrm{c}}$, Jean-Claude Maki Mateso ${ }^{\mathrm{d}, \mathrm{e}}$, Gerard Govers $^{\mathrm{a}}{ }$ Olivier Dewitte $^{\mathrm{b}}$

${ }_{5}{ }^{a} K U$ Leuven, Department of Earth and Environmental Sciences, Division of Tourism and Geography (Celestijnenlaan 200E, 3001 Heverlee, Belgium)

${ }^{b}$ Royal Museum for Central Africa, Department of Earth Sciences (Leuvensesteenweg 13, 3080 Tervuren, Belgium)

${ }^{c}$ Université de Liège, Department of Geology (Allée du six août 14, 4000 Liège, Belgium)

${ }_{10}^{d}$ Université catholique de Louvain, Earth and Life Institute Environmental Sciences (Croix du Sud 2, B-1348 Louvain-la-Neuve, Belgium)

${ }^{e}$ Centre de Recherche en Sciences Naturelles, Department of Geophysics (Lwiro, DR Congo)

\begin{abstract}
Predicting the occurrence of landsliding is of key importance for understanding the geomorphological development of mountain environments as well as to assess the potential risk posed by landsliding to human societies in such environments. Global landslide susceptibility models use a generic model formulation to predict landslide susceptibility anywhere on the planet from openly available data. Regional models, on the contrary, use local information on landslide occurrence to constrain model parameters and may also benefit from better spatial information with respect to controlling factors. This study aims to investigate the added value of the construction of regional landslide susceptibility models (versus global and continental models) in the western branch of the East African Rift, a data-scarce landslide-prone tropical environment. First, a comprehensive landslide database containing 6446 instances was compiled for the study area using Google Earth imagery. Second, three regional data-driven landslide susceptibility models were developed. Third, the efforts to construct these regional models were quantified by analysing how their quality is impacted by (1) the use of more accurate, regional peak ground acceleration and geology data, and (2) an increasing inventory size. Fourth, regional and global/continental models were compared in terms of predictive power and geomorphological plau-
\end{abstract}

\footnotetext{
Email address: arthur.depicker@kuleuven. be (Arthur Depicker)
}

November 4, 2020 
sibility. We observe that global/continental landslide susceptibility models are capable of identifying landslide-prone areas, but lack prediction power and geomorphological plausibility when compared to our regional models. Importantly, this difference in quality is not driven by the use of more accurate and detailed geology and peak ground acceleration data, but rather by the use of a detailed regional landslide inventory to calibrate the models. We also show that the model quality only increases marginally beyond a certain inventory size. We conclude that the regional landslide susceptibility assessment does provide an added value compared to existing global models in terms of geomorphological plausibility and model performance, whereby the largest gain is to be found in the construction of a regional landslide inventory, rather than the investment in more detailed covariates or the application of more complex modelling techniques. The latter suggests that the role of controlling variables depends, to some extent, on the regional context: making adequate susceptibility predictions proves difficult when local conditions are not accounted for by means of a regional inventory.

Keywords: Landslide inventory, statistical modelling, model complexity, Google Earth, tropical environment

\section{Introduction}

Predicting the landslide occurrence is of key importance for understanding the geomorphological development of mountain environments as well as to assess the potential risk posed by landsliding to human societies in such environments, as landslides lead to thousands of casualties per year and significant damage to the environment and infrastructure, especially in developing countries (Korup et al. 2010, Larsen \& Montgomery, 2012, Walker \& Shiels, 2013, Froude \& Petley, 2018). Despite this, for most regions, landslide susceptibility (LSS) has only been assessed using global and continental models (Nadim et al., 2006.

25 Hong et al., 2007, Stanley \& Kirschbaum, 2017; Lin et al., 2017, Broeckx et al. 2018). While these models are certainly useful to detect and quantify differences 
between regions, their suitability to assess spatial variations within regions is questionable due to three reasons: (1) these models have not been validated in the regions concerned, (2) they are often based on the combination of few and simplified readily available covariates which might be sufficient to reflect broad continental/global patterns, but not necessarily detailed regional ones, and (3) when they are data-driven, they rely on a combination of available, regional datasets. Such a dataset may not be representative for a region in which no such data are available.

In general, LSS models are based on data-driven methods (e.g. logistic regression (LR) and random forests $(\mathrm{RF})$ ), which rely on a landslide inventory to construct and validate the model Corominas et al., 2014, Reichenbach et al. 2018). Building a data-driven regional LSS assessment is time-consuming. This is particularly the case in tropical Africa where the construction of landslide in-

40 ventories is impeded by fast land rehabilitation (especially in rural areas), poor field accessibility, and a lack of access to very-high-resolution remote sensing imagery (Monsieurs et al., 2018, Jacobs et al., 2018).

More specifically, the western branch of the East African Rift (WEAR) is a tropical environment where society is highly impacted by landslides, yet, at the same time, data on the spatial and temporal distribution of landslide occurrence is scarce for this region (Maki Mateso \& Dewitte, 2014, Jacobs et al., 2016 Monsieurs et al. 2017). One may question the potential of global/continental models to accurately predict the frequency and the spatial distribution of landslides in this environment as the calibration of these models is based on landslide inventories mainly collected in different environmental settings (different climate, geology and/or geomorphology). This particular region is, therefore, suitable to address our primary research question, i.e. does a regional LSS model, based on local data and local landslide inventory significantly outperform global/continental models in terms of predicting the spatial distribution 55 of landslides, and if so, can we identify which factors contribute most to the improved performance? First, we look at how the predictive power is impacted by (i) the size of the landslide inventory, (ii) the accuracy of spatial covariates, and 
(iii) the choice of the modelling technique. Second, a quantitative and qualitative comparison of the regional LSS model with global and continental models is made in order to assess their respective predictive power and relevance in terms of geomorphologic plausibility.

\section{Methods}

\subsection{Study area}

\subsubsection{Geological setting}

The study focuses on a part of the WEAR subject to active continental rifting. More specifically, we focus on the northern part of Lake Tanganyika and the Kivu Rift (Fig. 1), where rifting was initiated about 11 Ma due to the divergence of the Nubia and Victoria Plate (Delvaux \& Barth, 2010, Saria et al. 2014, Pouclet et al., 2016). The Kivu rift currently opens up at a rate of 2

$70 \mathrm{~mm} / \mathrm{yr}$ (Saria et al. 2014) and is associated with active volcanism and seismic activity (Smets et al., 2016, Delvaux et al., 2017).

The study area has a diverse and complex geology, whereby most rock outcrop dates from the Mesoproterozoic, consisting mainly of granites, quartzites, and pelites. The southwestern part of the region is dominated by gneisses, micaschists, and granites of Paleoproterozoic age. Meanwhile, Quaternary basaltic volcanism has been responsible for the formation of the Virunga volcanic massif north of Lake Kivu (Delvaux et al. 2017). This process led to the damming of the originally north-oriented drainage of the Kivu Basin and the establishment of a new south-directed rapidly incising drainage system connecting Lake

so „Kivu with Lake Tanganyika through the Ruzizi valley (Ross et al., 2014; Delvaux et al. 2017). Slightly methamorphosed glacial deposits of Neoproterozoic (Cryogenian) age occur in a synclinorium along the western shores of Lake Kivu and extend $200 \mathrm{~km}$ further south (Villeneuve, 1976, Delvaux et al. 2017).

\subsubsection{Landslides in the WEAR}

Our study area is characterised, on the one hand, by steep slopes and seismic activity due to rifting processes, and, on the other hand, by high rainfall 
amounts. These factors are considered to be the main triggers of landsliding globally (Casagli et al., 2017; Delvaux et al., 2017; Monsieurs et al., 2018). It is therefore not surprising that global and continental studies have identified

90 the study area as being prone to landsliding (Hong et al., 2007; Stanley \& Kirschbaum, 2017; Lin et al., 2017; Broeckx et al., 2018). This was confirmed through recent local studies using field observations and aerial photography (e.g. Maki Mateso \& Dewitte, 2014; Mugaruka Bibentyo. et al., 2017, Nibigira et al. 2018, Nobile et al. 2018, Kubwimana et al., 2018). However, field observations in the study region were hitherto focused on a limited area (Bukavu, Bujumbura, and the west coast of Lake Kivu) and no regional landslide inventory or LSS assessment is currently available.

Previous studies also showed that, despite the potential role of seismicity, the majority of recent landslides within the WEAR appear to be triggered by large rainfall events rather than seismic activity (Monsieurs et al., 2018). The high population growth in recent decades (with a current estimated population density larger than $200 \mathrm{inh} . / \mathrm{km}^{2}$ ) is putting a huge pressure on the natural environment through deforestation, road construction, and mining activity. These problems are certainly to be considered when attempting to explain the spatial distribution of recent landslides (Linard et al., 2012, Stevens et al., 2015. Michellier et al., 2016, Monsieurs et al., 2017, 2018, WorldPop, 2017).

\subsection{Landslide mapping from Google Earth}

The landslide inventory was compiled for the entire study area through the visual interpretation of Google Earth imagery, a technique that has proven to be adequate in many areas (Corominas et al. 2014). For $97.4 \%$ of the study area, at least one very-high-resolution (roughly 0.3-0.6 m) cloud-free satellite image was available for the period between 2000 and 2018, provided by either DigitalGlobe (www.digitalglobe.com/) or CNES Airbus (www.intelligence-airbusds. com/). In some places, such as Bujumbura and Bukavu, detailed coverage for five or more consecutive years was available. A similar search time per cloud-free area ratio was applied on each Google Earth image, hence areas with a higher 


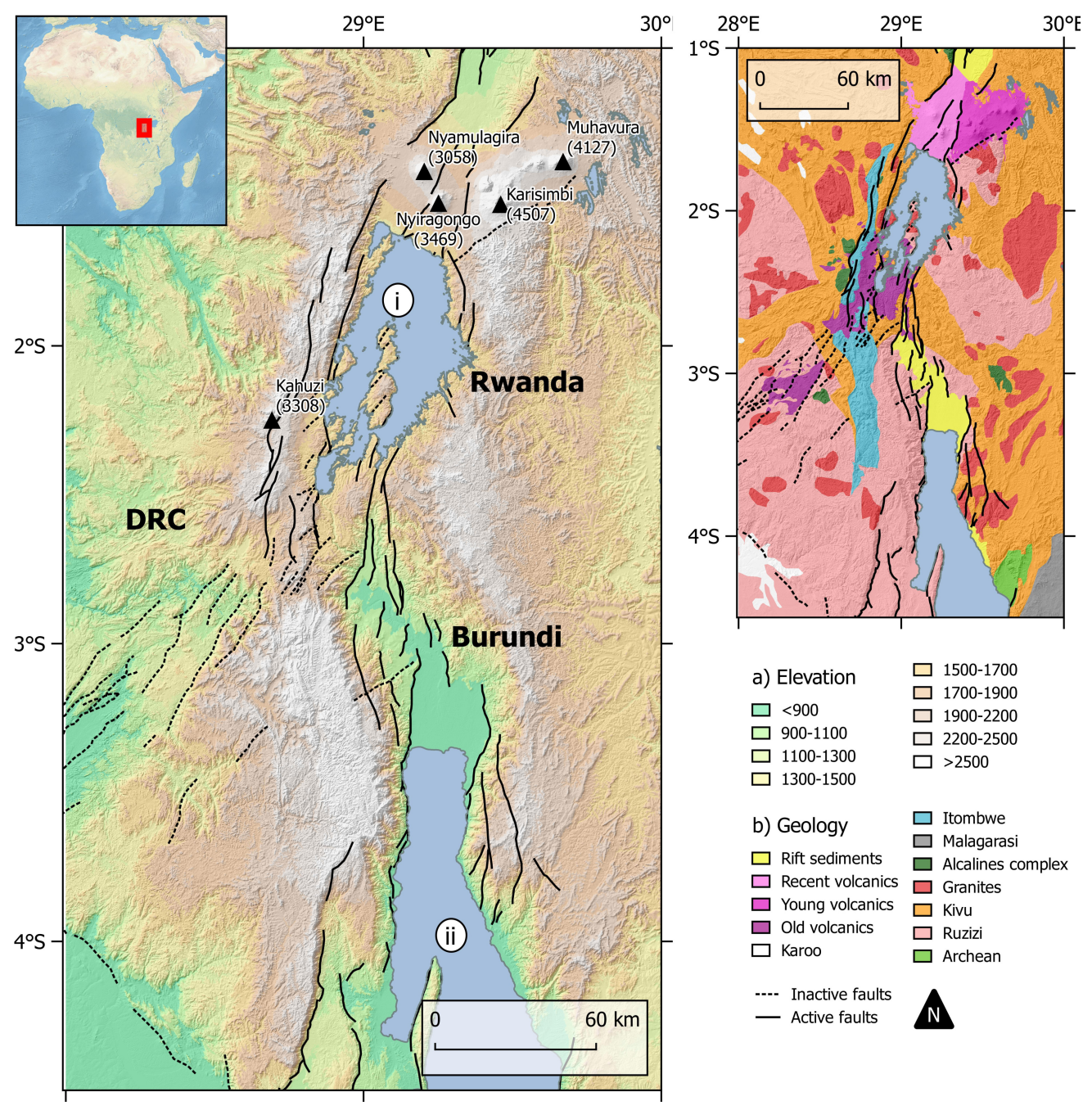

Figure 1: a) Elevation in the Kivu Rift region at the 1" $( \pm 30 \mathrm{~m})$ resolution: (USGS, 2006a) b) Geology (lithostratigraphical units and faults) in the Kivu rift region (Laghmouch et al., 2018). More info with regard to the approximate age, chronostratigraphy, and main lithological constitution of the units is provided in Section 2.4 and Table 1. Letters in the lakes: $\mathrm{i}=$ Lake Kivu, ii = Lake Tanganyika. The hillshade was derived from the 3" SRTM data (USGS, 2006b). 
imagery density were investigated more thoroughly. In general, landslides can be recognised by their spectral footprint and/or by the morphological changes in the landscape due to the depletion and accumulation of slope material, made visible through the 3D terrain visualisation. The extent of each landslide was drawn as a polygon including the depletion and accumulation zone. To each landslide we manually assigned (a) an initiation point in the depletion zone to extract environmental characteristics and (b) two points adjacent to the feature to approximate the average slope conditions prior to failure. A differentiation between 'shallow' and 'deep-seated' landslides was made, whereby the depth of shallow landslides did not exceed more than a couple of meters (e.g. Sidle \& Ochiai, 2006, Roering et al., 2003). Sliding depth was estimated based on our observations in the field for a few hundreds of landslides. While this may have certainly led to errors, the approximate slide depth can in most cases readily be established by examining the shape and the size of both the landslide scar and the deposits. The date of the first image where the landslide is visible is taken as a proxy for the date of occurrence of the landslide, except if the image was the first of a time series. In addition, we attempted to identify the landslide trigger, which could be either rainfall or seismic activity. This was done through in situ field observations and cross-checking with databases for seismic activity and rainfall-induced landslides Monsieurs et al. (2018); Oth et al. (2017)

Malamud et al. (2004) showed that the frequency of landslide surface areas in a complete inventory mimics the shape of an inverse gamma $(\Gamma)$ distribution. In other words, if the inventory for a certain area displays strong deviations from this function (assessed through the Kolmogorov-Smirnov test), it may be considered as 'non-complete' and less representative for landslide occurrence in that region. Hence, in order to assess whether the inventory was biased by unequal satellite imagery cover, land rehabilitation, and/or erosion, the landslide area frequency density was fitted to the inverse $\Gamma$ function. First, this was done for the entire database. Second, the same procedure was repeated for deepseated and shallow landslides separately. This way, it could be assessed whether both process types, which might be controlled by very different factors, were 
represented well in the inventory.

\subsection{Landslide susceptibility modelling} and support vector machines (SVM). These approaches were then compared in terms of model quality. The models were trained using the sklearn package (pypi.org/project/sklearn/) in a Python 3.4 environment (www.python.org/).

』 The first technique, LR, is an excellent tool to predict binary events Hosmer 155 \& Lemeshow, 2000), and is applied more than any other technique in the context of LSS modelling (Budimir et al., 2015, Reichenbach et al., 2018). The basic equation of $\mathrm{LR}$ is:

$$
\log \left(\frac{P}{1-P}\right)=\alpha+\sum_{i=1}^{n} \beta_{i} X_{i}
$$

where $P$ represents the likelihood of landslide occurrence, $\alpha$ is the intercept of the linear model, $X_{i}$ represents $i$-th of $n$ predictors, and $\beta_{i}$ the accompanying coefficient that has to be fitted to the data. The dependent variable $P$ will take values in a continuous range between 0 and 1 .

The RF algorithm is a method that has gained attention in recent landslide literature (e.g. Catani et al., 2013, Steger et al., 2016). This supervised machine learning algorithm is based on the combination of a large number of tree predictors, each one of them trained on an independent random sample of observations and with a random set of predictors. For a binary classification problem $(0 / 1)$, a score is produced by averaging the prediction over all trees (Breiman, 2001).

1 The SVM can be used for both regression and classification problems (Vap170 nik, 1995) but has not received much consideration in landslide literature until recently (e.g. Goetz et al., 2015; Steger et al., 2016). Nevertheless, the technique has been used in many fields such as image classification and pattern recognition (Ma \& Guo, 2014), and has been proven to be reliable and stable, especially for smaller training datasets (Huang et al. 2002, Chi et al., 2008). In the context of 
175 a binary classification problem and linear separability of the classes, the SVM algorithm determines a hyperplane in the predictor space that shows optimal discrimination between the two classes, i.e. the distance between the hyperplane and the closest observations of both classes (i.e. the support vectors) is maximised. If the two classes are not linearly separable in the predictor space, the latter is transformed into a higher-dimensional predictor space by means of a so-called kernel function until such a hyperplane can be found (Vapnik, 1995). Within this study, we trained the SVMs with the radial basis function (RBF) kernel (e.g. Peng et al., 2014: Steger et al., 2016). Moreover, the SVM is determined by two hyperparameters $\gamma$ and $C$, which, for each model run, were tuned with a grid search (Hsu et al., 2016).

LSS prediction is a one-class classification problem, where the only data available refers to observed landslides. In other words, all observations for the dependent variable in the landslide inventory are of identical class. By sampling random locations in the study area and classifying them as 'nonlandslide points', the classification problem becomes binary (landslide/nonlandslide $1 / 0$ ). For the training and validation of all models presented below, an equal shares sampling design for the landslide/non-landslide data was applied (e.g. Petschko et al., 2014b Steger et al., 2016).

\subsection{Predictors}

Based on the work of Reichenbach et al. (2018), with regard to morphology, we derived a set of seven predictors (slope, north exposure, east exposure, planar curvature, profile curvature, distance to the next river, and roughness) from the 1" $( \pm 30 \mathrm{~m})$ resolution SRTM elevation model (USGS, 2006a). The SRTM flevation data displays a vertical error of a few meters on average (Rodriguez 200

C. E. \& Belz, 2006). When other variables such as slope and aspect are computed from this DEM, this error is propagated and aggravated. However, it has been shown that this derived error is relatively small for steep slopes. Flatter areas can display a more considerable error, especially with regard to the aspect (Florynski, 1998, Zhou \& Liu, 2008). We excluded the trivial areas, such as 
flat areas (with a slope $<10$ ), from the analysis, as they inflate reported model performance (Brenning, 2012).

From the DEM, the distance to the drainage network was derived as a hydrological predictor. This predictor served as a proxy for the oversteepening of slopes due to river incision, which might be underestimated by the SRTM DEM but can result in landsliding (Schmidt \& Montgomery, 1995, Burbank et al. 1996). The computation of the drainage network in flatter areas, such as the Ruzizi river plain between Lake Kivu and Lake Tanganyika, was sensitive to errors in the DEM and its derivatives (Dewitte et al., 2010). Hence, the drainage network had to be digitised manually in these regions.

For the land cover (LC), the $20 \mathrm{~m}$ resolution ESA CCI Land Cover model was used (ESA, 2016). A total of six LC classes were recognised within the study area: tree cover, cropland, grassland, shrubs cover, bare areas, and built-up areas. The use of LC as a predictor in LSS models is debated. The LC conditions observed now might not be similar to the conditions that were present at the time of slope failure (van Westen et al. 2006, Petschko et al., 2014a). Moreover, the type of LC could impart a bias in the inventorying of the landslides (Montgomery et al. 2000, Petschko et al., 2016). However, it is also well known that changes in LC due to human activity may change the landslide hazard: deforestation may increase the rate of slope failure (Jakob, 2000, Montgomery et al. 2000), which is also the case for mining and urbanisation (Gill \& Malamud, 2017). Given the importance of these activities in the study area over the last decades (Basnet \& Vodacek, 2015), we incorporated LC in our models.

Four different geological predictors were evaluated: lithostratigraphy, peak ground acceleration (PGA), distance to the nearest active fault, and distance to the nearest inactive fault. The active faults are related to the recent Rift formation (late Cenozoic), while the inactive faults predate the WEAR (Paleozoic to early Cenozoic). Several studies have concluded that lithology has a strong impact on the spatial variation of landslide prevalence, type, and depth (Henriques et al., 2015). Based on the work of Laghmouch et al. (2018) and field knowledge, we produced a new regional lithostratigraphical map for the 
WEAR, being the product for the region with the highest resolution (Fig. 1). A total of 12 classes were distinguished (Table 1).

The PGA and the distances to the fault systems serve as a proxy for seismotectonic activity (e.g. Wilson \& Keefer, 1985; Khazai \& Sitar, 2004), which has been widely recognised as a contributor to slope failure, either directly as a trigger (Ugai et al., 2012; Casagli et al., 2017) or indirectly by weakening the substrate (Marc et al., 2015, Vanmaercke et al., 2017). Especially for large deepseated old landslides, which are the remnants of long-term landscape evolution, we assume that at least some are earthquake-triggered. Delvaux et al. (2017) conducted a seismic hazard assessment for the study area, resulting in a $2.2 \mathrm{~km}$ resolution PGA model that we used in this study. The distance to the fault systems was derived from a layer composing of active and inactive fault systems (Smets et al., 2016, Delvaux et al., 2017).

Rainfall, especially extreme events during the wet seasons, is considered to be a key trigger of recent observed landslides in the region (Jacobs et al. 2018 , Monsieurs et al. 2018). As a landslide predictor, we used the frequency of accumulated rainfall threshold exceedance within a certain period. We used two day and the 10 day periods (e.g. Pasuto \& Silvano, 1998, Aleotti, 2004) and the respective threshold values for these durations were 15 and $25 \mathrm{~mm}$. These 255 numbers were derived from the threshold model proposed by Rossi et al. (2017) and calibrated with the least squares method (Eq. (2)).

$$
T=4.6 D^{0.31},
$$

where $T[\mathrm{~mm}]$ is the accumulated rainfall threshold in function of the preceding period $D[\mathrm{~h}]$. Rainfall data was extracted from the TAMSAT database (data from 2005 to 2015) at a $4 \mathrm{~km}$ resolution (Tarnavsky et al., 2014, Maidment 260 et al. 2014, 2017).

In total, a set of 14 variables was evaluated for the susceptibility analysis (Table 22. Prior to the calculations, all layers were resampled to the resolution of the SRTM elevation data (1" or roughly $30 \mathrm{~m}$ ), a common practice in LSS literature (Reichenbach et al. 2018). Moreover, Jacobs et al. (2018) conducted 


\begin{tabular}{|c|c|c|c|}
\hline Age & Chronostratigraphy & Lithostratigraphy & Main lithological constitution \\
\hline $10 \mathrm{Ka}$ - present & Late Quaternary & Recent volcanics & $\begin{array}{l}\text { lava, tuff, and ash, deposited in the past } \\
\text { decades and centuries, a result of eruptions of } \\
\text { the Nyiragongo and Nyamulagira. }\end{array}$ \\
\hline 2-1 Ma & Early Quaternary & Young volcanics & Relatively fresh basalts, deposited $\pm 2 \mathrm{Ma}$ ago. \\
\hline $12-6 \mathrm{Ma}$ & Neogene & Old volcanics & $\begin{array}{l}\text { Highly weathered basalt, deposited 11-4 Ma } \\
\text { years ago. }\end{array}$ \\
\hline $23 \mathrm{Ma}$ - present & Late Cenozoic & Rift sediments & Sand along the lake or swamps more inland. \\
\hline 360-201 Ma & \multicolumn{2}{|l|}{ Karoo } & Black shales, tillite, not metamorphosed. \\
\hline \multirow[t]{2}{*}{$1000-540 \mathrm{Ma}$} & \multirow[t]{2}{*}{ Neoproterozoic } & Itombwe & $\begin{array}{l}\text { Black shales, tillite, silicified tillite, weakly } \\
\text { methamorphosed. }\end{array}$ \\
\hline & & Malagarasi & $\begin{array}{l}\text { Black shales, tillite, silicified tillite, weakly } \\
\text { methamorphosed. Presence of dolomites and } \\
\text { volcanic rocks (basalts). }\end{array}$ \\
\hline $820-720 \mathrm{Ma}$ & \multirow[t]{3}{*}{ Mesoproterozoic } & Alcalines complex & $\begin{array}{l}\text { Granitic rocks, intrusive volcanic rocks (rhyo- } \\
\text { lite). }\end{array}$ \\
\hline 1375-980 Ma & & Granites & two mica and leuco-granites. \\
\hline 1600-1000 Ma & & Kivu & $\begin{array}{l}\text { Pelites, quartzopelites, and quartzites at dif- } \\
\text { ferent degrees of weathering. Moderately } \\
\text { metamorphosed. }\end{array}$ \\
\hline $2500-1600 \mathrm{Ma}$ & Paleoproterozoic & Ruzizi and ante-Ruzizi & $\begin{array}{l}\text { Gneiss and micaschists, prone to chemical } \\
\text { weathering, and quartzites, resistant to weath- } \\
\text { ering. Strongly methamorphosed. }\end{array}$ \\
\hline $4000-2500 \mathrm{Ma}$ & \multicolumn{2}{|l|}{ Archaen } & $\begin{array}{l}\text { Gneiss and micaschists, prone to chemical } \\
\text { weathering, and quartzites, resistant to weath- } \\
\text { ering. }\end{array}$ \\
\hline
\end{tabular}

Table 1: Lithostratigraphical units in the WEAR, presented in chronological order, and based on the work of Laghmouch et al. (2018). Note that this table is only valid for the study area, and not the entire WEAR. 

of our study area, and concluded that this resolution led to the best results.

The predictors were tested for multicollinearity, i.e. whether there were predictors that can be described as a linear combination of one or more other predictors. Multicollinearity will lead to a decrease in the precision of coeffihave a negative effect on hypothesis testing and forecasting. The presence of multicollinearity between two or more variables was assessed by calculating the condition indices. A high condition index $(>10)$ indicates possible problematic multicollinearity. If two or more variables have a high variance decomposition and only one of them should be retained in the model (Belsley et al., 2005).

\subsection{Quality assessment and variable importance}

To assess the model quality, we used the Area Under the Curve (AUC) of the Receiver-Operating-Curve (ROC) (Bradley, 1996, Brenning, 2012). The

for the validation datasets was considered to be the overall average AUC (Hastie et al. 2009, Brenning, 2012). This technique, compared to regular validation with one possible model, reduces the variation in the assessed model quality (Jung, 2018). A second performance measure was calculated through spatial 


\begin{tabular}{|c|c|c|c|c|}
\hline Theme & Predictor & Units & Res. & Source \\
\hline \multirow{6}{*}{ Morphology } & Slope & $\circ$ & $1 "$ & \multirow{7}{*}{ SRTM } \\
\hline & North exposure & - & $1 "$ & \\
\hline & East exposure & - & $1 "$ & \\
\hline & Profile curvature & $m^{-1}$ & $1 "$ & \\
\hline & Planar curvature & $\mathrm{m}^{-1}$ & $1 "$ & \\
\hline & Roughness & $\mathrm{m}$ & $1 "$ & \\
\hline Hydrology & $\begin{array}{l}\text { Distance to } \\
\text { drainage }\end{array}$ & $\mathrm{m}$ & $1 "$ & \\
\hline $\mathrm{LC}$ & $\mathrm{LC}$ & - & $20 \mathrm{~m}$ & ESA CCI \\
\hline \multirow{4}{*}{ Geology } & Lithostratigraphy & - & $1 "$ & - \\
\hline & $\begin{array}{l}\text { Distance to active } \\
\text { faults }\end{array}$ & $\mathrm{m}$ & $1 "$ & \multirow{2}{*}{$\begin{array}{l}\text { Smets et al. (2016) } \\
\text { \& Delvaux et al. } \\
2017)\end{array}$} \\
\hline & $\begin{array}{l}\text { Distance to inactive } \\
\text { faults }\end{array}$ & $\mathrm{m}$ & $1 "$ & \\
\hline & PGA & $\mathrm{m} \mathrm{s}^{-2}$ & $2.2 \mathrm{~km}$ & Delvaux et al. (2017) \\
\hline \multirow{2}{*}{ Other } & $\begin{array}{l}2 \text { day } 15 \mathrm{~mm} \\
\text { rainfall exceedance }\end{array}$ & - & $4 \mathrm{~km}$ & \multirow{2}{*}{ TAMSAT } \\
\hline & $\begin{array}{l}10 \text { day } 25 \mathrm{~mm} \\
\text { rainfall exceedance }\end{array}$ & - & $4 \mathrm{~km}$ & \\
\hline
\end{tabular}

Table 2: Landslide predictors evaluated for the susceptibility analysis, themes according to Reichenbach et al. (2018). 
$\mathrm{CV}$, only this time the data subsets were not generated randomly. Instead, the data was split according to 10 sub-regions of the study area (Rwanda, Burundi, and 8 administrative zones in the DRC). This technique allowed to assess the transferability of the models to new regions (Dewitte et al., 2006; Brenning, 300 2012, Petschko et al., 2014b, Steger et al., 2016). Note that within the CV and SCV, the hyperparameters for the SVM model were tuned for each crossvalidation training set.

Although the AUC is a good indication, it does not serve as a stand-alone measure for model quality. Firstly, it has been shown that high AUC values can be achieved with unrealistic LSS maps, and secondly, a reduction of the database quality through the inclusion of a bias could enhance the predictive performance (Steger et al., 2016).

Therefore, we made an assessment of the model sensitivity to variations in the training dataset. For each of the three considered modelling techniques, 30 models were trained, each time using a different and random inventory subset of size $N$, whereby $N$ is the minimal number of landslides in the training data necessary to build a model of acceptable quality (Section 2.6). Finally, for each approach a scatterplot was derived, whereby each point represented a pixel, showing the prediction variance on the y-axis and the prediction average on the 315 x-axis. A smaller variance indicated that the model's predictions were more robust.

In order to gain a better insight into the landslide process, we also examined the importance of the variables in the different modelling approaches was examined. The importance of each predictor $i$ was assessed by constructing univariate LSS models and calculating their $\mathrm{AUC}_{i}$. The higher this univariate $\mathrm{AUC}_{i}$, the more variability in the spatial distribution of the landslides explained by the predictor. For each predictor, the $\mathrm{AUC}_{i}$ was averaged using 10-fold SCV.

The impact of each predictor was also quantified by means of the odds ratio (OR), a derivative from the LR model. In the case of continuous predictors, 325 the $\mathrm{OR}$ reflects the increase $(\mathrm{OR}>1)$ or decrease $(\mathrm{OR}<1)$ in odds when the 
predictor's value is augmented with a predefined step. For categorical variables, such as lithostratigraphy and LC, an OR is defined for each class $i$ of this predictor, and with reference to a base class ${ }_{r e f}$. The OR of each class $_{i}$ then reflects the increase in odds when the predictor alters from class $\mathrm{ref}_{\text {ef }}$ to class $i$, while all other predictors are given a constant value (Kleinbaum \& Klein, 2011).

2.6. Generating added value through regional LSS: model choice, inventory, or covariates?

The LSS models are determined by three components: the model architecture, the landslide inventory, and the spatial covariates and their accuracy. Methods to compare the added value of the different modelling techniques, which are not all as straightforward to implement as LR, are described in Section 2.5.

To estimate the number of landslides $N$ in the inventory above which there is no significant improvement of the model quality, the three different models were evaluated with increasing (calibration) database sizes. To reduce the simulation time, the step size increased with the database size. For each database size $n, 30$ iterations were performed. During each iteration, the model quality, expressed as the AUC, was assessed through 10-fold $\mathrm{CV}$ and SCV, each time using $n$ landslide samples and $n$ random non-landslide samples as training data.

The added value of more accurate covariates, specifically PGA and lithostratigraphy, was assessed through the impact on the model quality when their global counterparts, as used by Broeckx et al. (2018), were integrated into the model instead. The three different models were reconstructed with the global PGA model proposed by Giardini et al. (1999), and the global lithology dataset proposed by Hartmann \& Moosdorf (2012).

\subsection{Comparing regional and continental/global LSS models}

The best regional LSS model, selected through the quality assessment, was compared to a global and a continental LSS model. The global LSS model was developed by Stanley \& Kirschbaum (2017) and covers the entire globe. This model combined data on slope, fault, geology, forest loss, and road networks 
the AUC. For the global models, this was calculated using the entire inventory as validation data. Secondly, the prediction rates of the different models were compared. For each model, the rate is calculated as the proportion of landslides in function of the proportion of the study area with the highest LSS Chung 365 \& Fabbri, 2003). Lastly, since a high quantitative model performance does not necessarily correspond to a high geomorphological plausibility (Dewitte et al. 2010; Steger et al., 2016), the regional and global LSS models were compared visually, after dividing the area into susceptibility classes. For each LSS model, the highest LSS class constituted of the $10 \%$ of the entire study area with the highest LSS. The lowest LSS class contained the $40 \%$ of the study area with the lowest LSS, while the two intermediary LSS classes covered 20 and $30 \%$.

\section{Results and discussion}

\subsection{Landslide inventory}

We compiled an inventory of 6446 landslides (Fig. 2). Some landslide examples are displayed in Fig. 3 . Figures $3 \mathrm{~b}$ and $3 \mathrm{~d}$ illustrate how slope failures were detected predominantly by the spectral signature of the LC changes that followed the event.

The deep-seated landslides represented $29 \%$ of the inventory. 198 of these landslides were larger than 5 ha. For most of these deep-seated landslides, initiation was not visible in the available Google Earth imagery, hence their timing and age could not be estimated. These deep-seated slope failures could be linked, on the one hand, to seismo-tectonic activity and rainfall, and, on the other hand, to intrinsic slope evolution and its associated weathering and river 
incision (Dille et al. 2019). However, these are just basic assumptions, and this hypothesis would need further analysis (out of the scope of this research).

The shallow landslides represented $71 \%$ of the inventory and were smaller than 1 ha in more than $99 \%$ of the cases, the smallest detectable landslide being $6.35 \mathrm{~m}^{2}$. We observed that their spectral footprint tends to disappear within a time-span of a few years. Some landslides in cropland were no longer visible after one year, while the footprint in forest could be preserved for more than a decade. The vast majority of landslides could therefore be classified as relatively recent, with a moment of origin at most a decade before the timing of the oldest high-resolution Google Earth image available for the concerned region. The majority of these landslides were triggered by rainfall. This was confirmed by a cross-check with the findings of Monsieurs et al. (2018), field observations in Western Rwanda and around Bukavu and Bujumbura, and the record of the recent seismic activity in the region (Oth et al., 2017). In total, 38 major landslide events triggered by rainfall were identified using Google Earth, where an event is defined as one or more consecutive days with landsliding (Rossi et al. 2010b). In one occasion, a rainfall event triggered more than 600 landslides in a few hours (event 5 in Fig. 2). For each event, all landslides were included in the database, as it was computed that even very large events with hundreds of instances do not lead to overfitting the model on a small portion of the study area (Supplementary Fig. S1). While we show that many shallow landslides are directly linked to rainfall conditions, we must acknowledge that human disturbance also plays a role. While the impact of human activities on landslide initiation is described in detail for several tens of reported landslides in the region by Monsieurs et al. (2017, 2018), we are at this stage unable to grasp the real impact of the changing LC and land use conditions on landslide initiation.

The inverse $\Gamma$ distribution fits well to the distribution of the deep-seated landslides ( $p=0.246$, Fig. 4). However, the distributions of the shallow landslides and of all landslides combined differed significantly from the inverse $\Gamma$ distribution ( $p<0.001$ and $p<0.001$, respectively), although visually they 
that there is a slight over-representation of very small landslides with an area of $\pm 100 \mathrm{~m}^{2}$. This may be due to the fact that human disturbance generates a disproportionately large number of small landslides (Van Den Eeckhaut et al. 2007). The powerlaws describing the decay in the tail of the distributions,

Figure 5 shows that LSS is highest along the rift flanks oriented towards Lake Tanganyika and Lake Kivu. The northwestern, southwestern, and eastern parts of the region are predicted to be less prone to landsliding by the various models we tested.

${ }_{440}$ The RF algorithm yielded the highest AUC, when calculated with CV (Table 3). The better performance of the model can be explained by the concentration of its higher LSS scores in a smaller area. Due to the non-landslide 


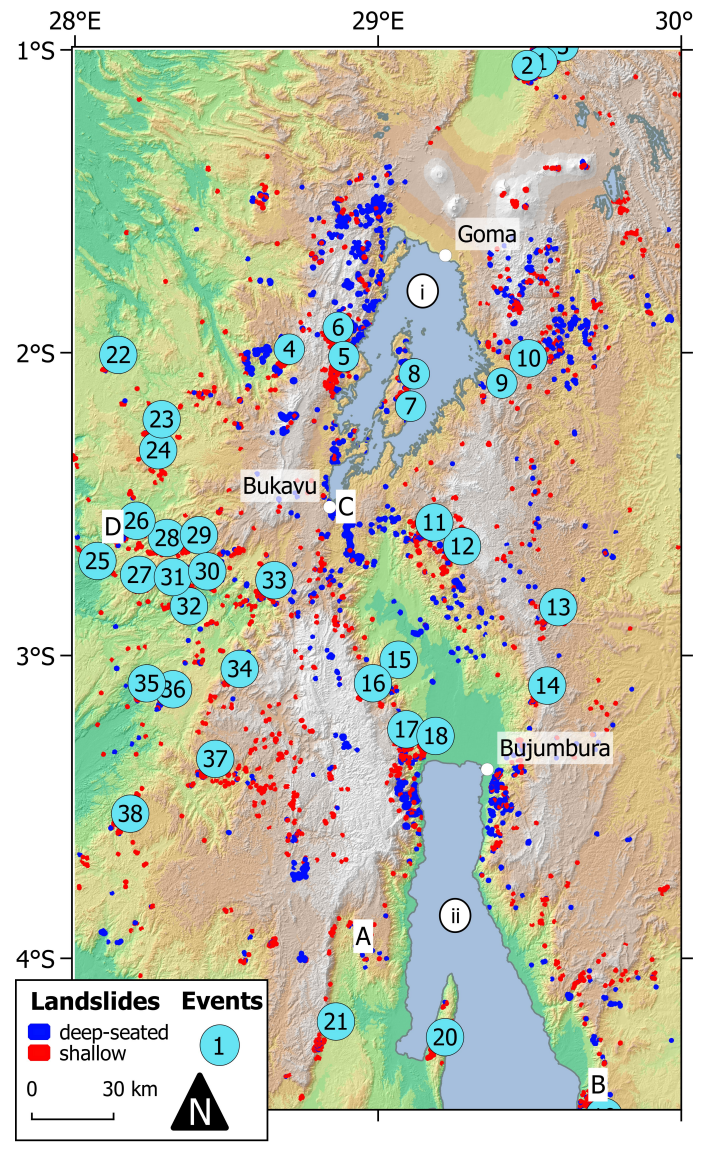

Figure 2: Spatial distribution of deep-seated and shallow landslides in the study area. $\mathrm{i}=$ Lake Kivu, ii = Lake Tanganyika. The capitalised letters represent the location of the images in Fig. 3 A = Fig. 3a, B = Fig. 3p, C = Fig. 3r, D $=$ Fig. $3 \mathrm{~d}$. 

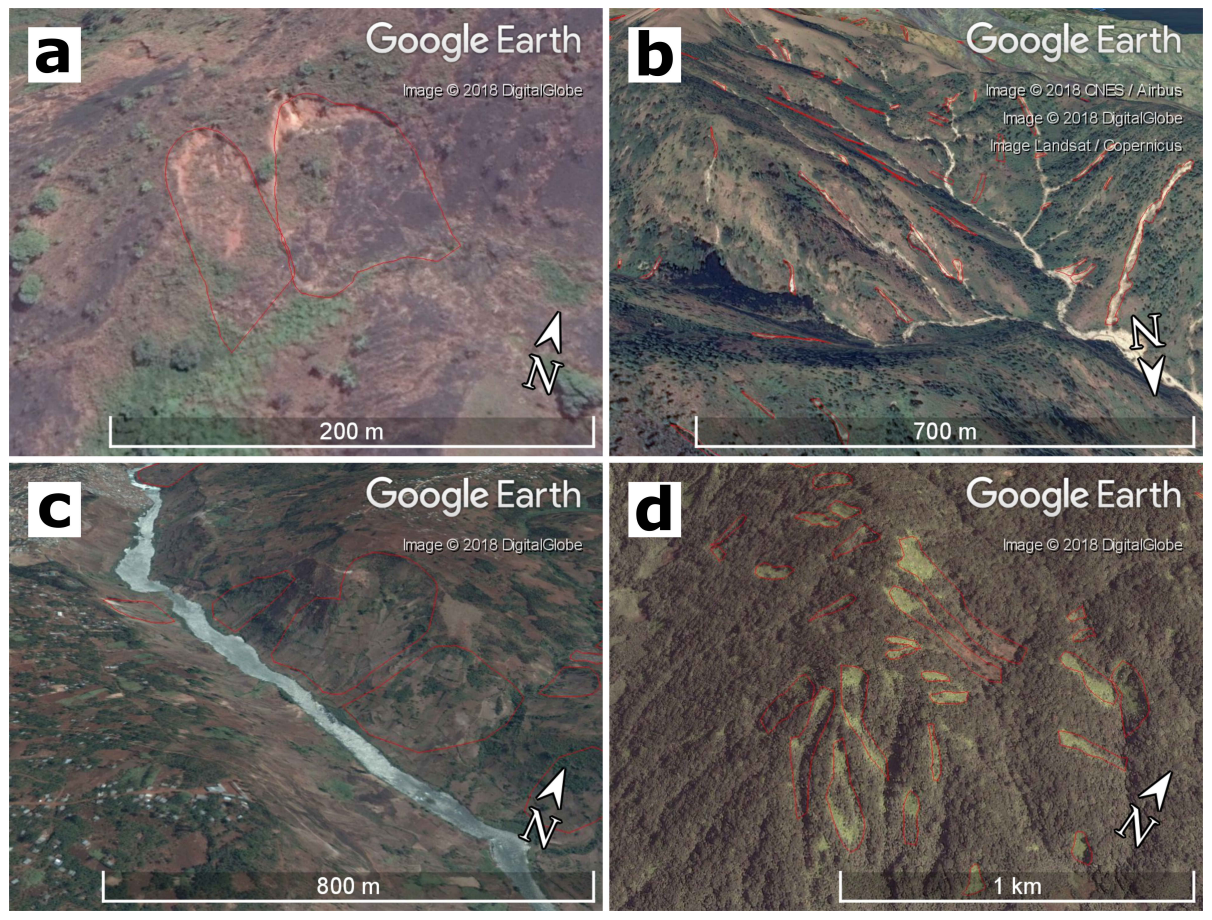

Figure 3: Oblique views of landslides in Google Earth imagery. The scales are approximate: (a) rotational slides, $\operatorname{DRC}\left(-3.960^{\circ} \mathrm{S}, 28.927^{\circ} \mathrm{E}\right)$ (b) debris flows and debris slides triggered by rainfall event 19 (Fig. 2), Tanzania $\left(-4.479^{\circ} \mathrm{S}, 29.698^{\circ} \mathrm{E}\right)(\mathrm{c})$ rotational slides at the Ruzizi river near Bukavu (DRC) and Rwanda $\left(-2.554^{\circ} \mathrm{S}, 28.882^{\circ} \mathrm{E}\right)$ (d) rainfall triggered landslides in rainforest (event 26 in Fig. 2p, DRC $\left(-2.603^{\circ} \mathrm{S}, 28.156^{\circ} \mathrm{E}\right)$. 


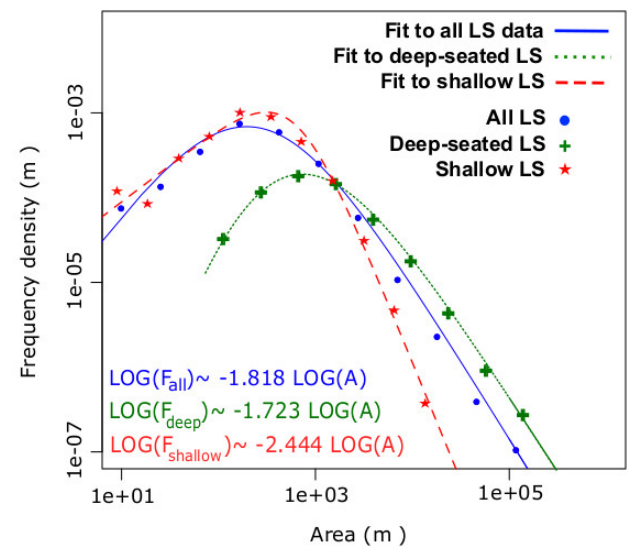

Figure 4: Frequency densities of the entire landslide inventory, the deep-seated landslides, and the shallow landslides, fitted to the inverse $\Gamma$ distribution. The powerlaw describing the slope of the lower tail of the distribution is displayed on the graph.

points being sampled randomly, fewer non-landslide instances would be "misclassified' because the higher LSS area is smaller, decreasing the number of commission errors and hence increasing the overall AUC. When SCV was used, the RF algorithm and LR were significantly outperformed by the SVM. These findings suggest that the RF model is more sensitive to overfitting compared to the SVM and its performance decreases when the model is extrapolated to new areas. Overall, the LR scores lower or equal to the machine learning algorithms, suggesting that this is not the optimal model for the LSS analysis in WEAR.

Visual inspection of the variance of the predictions (Fig. 6) shows that LR was least sensitive to variations in the training data. There is a seemingly parabolic relationship between the mean LSS prediction value and its variance for all three modelling techniques. For pixels with a very high or very low average 455 predicted LSS, the prediction is very stable and hence reliable, while there is more uncertainty for pixels with an intermediate predicted LSS Guzzetti et al. 


\begin{tabular}{|l|c|c|}
\hline Model & CV & SCV \\
\hline LR & 82.5 & 80.6 \\
\hline RF & 92.8 & 78.9 \\
\hline SVM & 91.6 & 84.3 \\
\hline
\end{tabular}

Table 3: Results (\%) for AUC of the logistic regression (LR), random forest (RF) and support vector machine (SVM) models, calculated with 10-fold crossvalidation $(\mathrm{CV})$ and spatial cross-validation $(\mathrm{SCV})$.

2006).

\subsection{Variable importance}

Although the variable hierarchy differs for the three models, a general pattern could be observed: slope was by far the most important predictor of LSS (Table 4). This is not unexpected, as relief is the ultimate driver of landslide activity (Schmidt \& Montgomery, 1995). Planar curvature of the terrain, LC, and the geological predictors PGA and distance to the active faults appeared to be of high importance as well, albeit less decisive than slope. Deforested and concave slopes tended to be the most landslide-prone. At first sight, it might seem strange that PGA and distance to active faults, proxies for seismicity, seemed to play a major role, despite our observation that all recent landslides were rainfall-triggered. However, for older as well as for larger landslides the trigger remains unidentified, hence a seismic trigger for these features cannot be ruled out. Another possible reason for the high importance of these variables could be the role of seismo-tectonic activity as a preparatory factor for landsliding, rather than a triggering factor. In other regions, it has been shown that seismo-tectonic activity weakens the substrate and hence decreases the slope „stability (Huang et al., 2013, Marc et al., 2015, Havenith et al., 2015b; Carlini 475 et al., 2016: Bucci et al. 2016, Vanmaercke et al., 2017). Most recent landslides are rather small (90\% is smaller than $2300 \mathrm{~m}^{2}$, and $50 \%$ smaller than 620 $\mathrm{m}^{2}$ ). Data also indicate that in recent years (since 2000) no major earthquakes 

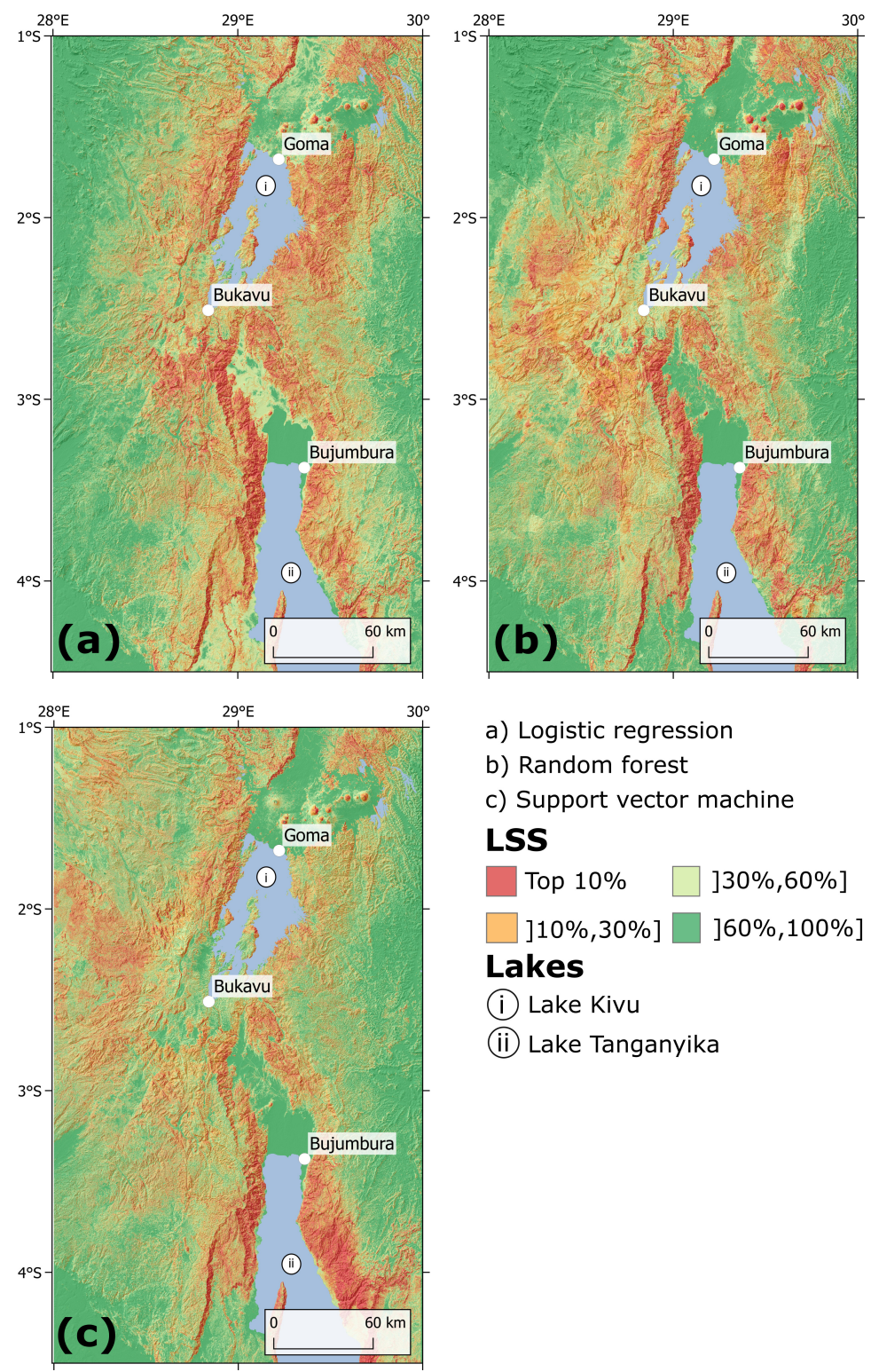
a) Logistic regression
b) Random forest
c) Support vector machine

\section{LSS}

Top 10\% $\square$ ]30\%,60\%]

]10\%,30\%] ] ]60\%,100\%]

\section{Lakes}

(i) Lake Kivu

(ii) Lake Tanganyika

Figure 5: LSS models derived from the three different data-driven approaches: (a) logistic regression (LR), (b) random forests (RF), and (c) support vector machines (SVM). 

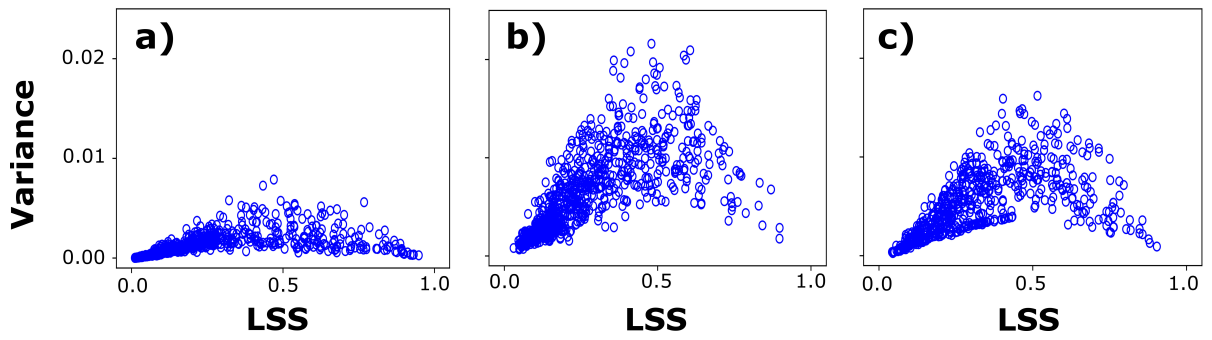

Figure 6: Prediction variance in function of the LSS for (a) logistic regression (LR), (b) random forests (RF), and (c) support vector machines (SVM) model predictions. For each modelling technique, 30 models were trained on a random sample of 500 landslides instances, i.e. the minimal training data size to assure acceptable model performance (Section 3.5).

$(M>7)$ occurred in the region (Oth et al. 2017). This suggests that major landslides are probably triggered by seismicity rather than by rainfall events, which appear to trigger predominantly small, shallow landslides (Chang et al. 2007: Saito et al., 2018).

Five variables were of intermediate importance: Rainfall (the two day 15 $\mathrm{mm}$ accumulated rainfall threshold exceedance), east- and north exposedness, distance to drainage, and profile curvature. Although the distance to inactive faults and lithostratigraphy displayed significant relations to LSS, their role in the different models seemed of little importance.

By looking at the ORs, a first observation was made regarding the basalts. The most recent basalts have a lower LSS than the young and old basalts (Table 5). This is explained by the degree of weathering which is extremely low for these recent deposits. The effect of age on weathering and slope stability has been reported in literature (e.g. Gallen et al., 2015, Roback et al., 2018). In line with research in other tropical regions, the most landslide-prone regions were those covered with unconsolidated rift sediments (Igwe, 2015). Here, the odds of landsliding were almost seven times higher than the odds of landslide occurrence in the metamorphic Kivu formations, which is the most common lithostratigraphy in the region. 


\begin{tabular}{|l|c|l|c|l|c|}
\hline \multicolumn{2}{|c|}{ LR } & \multicolumn{2}{c|}{ RF } & \multicolumn{2}{c|}{ SVM } \\
\hline Predictor & AUC $_{i}$ & Predictor & AUC $_{i}$ & Predictor & AUC $_{i}$ \\
\hline Slope & 80.0 & Slope & 73.7 & Slope & 82.0 \\
\hline dActive faults & 63.7 & Plan. curve & 61.7 & PGA & 70.1 \\
\hline PGA & 63.5 & LC & 61.0 & dActive faults & 69.7 \\
\hline LC & 60.9 & East & 56.9 & Rainfall & 62.8 \\
\hline Plan. curve & 59.3 & North & 56.7 & Plan. curve & 62.5 \\
\hline dDrainage & 55.8 & Rainfall & 55.4 & LC & 59.8 \\
\hline Prof. curve & 55.3 & dActive faults & 54.9 & dDrainage & 55.7 \\
\hline East & 52.9 & PGA & 53.4 & Prof. curve & 55.6 \\
\hline North & 52.8 & dDrainage & 52.0 & Lithostratigraphy & 55.0 \\
\hline Rainfall & 46.4 & Prof. curve & 50.0 & East & 54.2 \\
\hline Lithostratigraphy & 43.6 & Lithostratigraphy & 42.5 & North & 52.8 \\
\hline dInactive faults & 32.2 & dInactive faults & 39.3 & dInactive faults & 50.7 \\
\hline
\end{tabular}

Table 4: Importance of the predictors in three different models: logistic regression (LR), random forests (RF), and support vector machines (SVM). The relative importance of the variables is assessed through the comparison of the univariate $\mathrm{AUC}_{i}$. 
Compared to cropland, grassland, and built-up areas, the odds of landslide occurrence were up to 2 times lower in forest. This observation confirms previous literature stating that tree cover decreases the LSS by reducing the soil moisture through evaporation and slope reinforcement by roots (Sidle \& Bogaard, 2016). Forests cover large parts of the study area with a lower relief; this might have led to some confounding between slope and LC effects in our models.

3.5. Generating added value through regional LSS: model choice, inventory, or covariates?

An acceptable performance (Fig. 7) and a consistent LSS pattern (Supplementary Fig. S2 were obtained for all three regional modelling approaches with inventories of \pm 500 or more landslides. Further increasing the database size seems to have a negligible effect on models that relied on LR. For RF, the AUC kept increasing with approximate rates of $0.10 \% / 100$ instances for CV and decreasing marginally with $-0.01 \% / 100$ instances for SCV. This means that, in order to achieve a $1 \%$ increase in the AUC for the RF model, calculated with $\mathrm{CV}$, at least 1000 additional landslides have to be incorporated in the database. On the contrary, the negative rate when SCV is used indicates that increasing the database size decreases the discriminatory power of the model in new areas excluded from the model training. The AUC increment for the SVM model was 0.07 and $0.01 \% / 100$ instances, for $\mathrm{CV}$ and SCV respectively. Hence, the SVM benefits from a larger inventory to predict LSS both in areas that were included and excluded from model training, but the increase is very small when the model is tested in 'new' areas.

Our observations indicate that SVM succeeds slightly better at exploiting larger database sizes compared to RF and LR, but the gains in model quality are marginal for inventories larger than 500 landslides. This could be explained by the SVM having a higher model complexity, and hence being able to better capture the diversity of landslide processes in large databases without overfitting the model to the training data (Grayson et al. 2002). The latter may also explain the decrease in extrapolation ability of the RF model. 


\begin{tabular}{|c|c|c|c|c|c|}
\hline \multicolumn{2}{|c|}{ Variable } & OR & $\mathbf{C I}_{\text {lower }}$ & $\mathrm{CI}_{\text {upper }}$ & Step \\
\hline \multicolumn{2}{|c|}{ Slope } & 4.118 & 3.893 & 4.361 & 10 \\
\hline \multicolumn{2}{|c|}{ PGA } & 1.311 & 1.234 & 1.393 & 0.2 \\
\hline \multicolumn{2}{|c|}{ dFault active } & 0.878 & 0.863 & 0.894 & 5000 \\
\hline \multicolumn{2}{|c|}{ dFault inactive } & 1.037 & 1.029 & 1.044 & 5000 \\
\hline \multirow{11}{*}{ Lithostratigraphy } & Rift sediments & 6.825 & 5.245 & 8.913 & - \\
\hline & Recent volcanics & 0.000 & 0.000 & 0.000 & - \\
\hline & Young volcanics & 1.758 & 1.183 & 2.600 & - \\
\hline & Old volcanics & 1.359 & 1.041 & 1.775 & - \\
\hline & Karoo & 0.000 & 0.000 & 0.000 & - \\
\hline & Itombwe & 0.760 & 0.600 & 0.965 & - \\
\hline & Malagarasi & 0.069 & 0.004 & 0.342 & - \\
\hline & Alcalines complex & 0.132 & 0.050 & 0.310 & - \\
\hline & Granites & 1.162 & 0.990 & 1.365 & - \\
\hline & Ruzizi & 1.542 & 1.376 & 1.729 & - \\
\hline & Archaen & 0.605 & 0.317 & 1.141 & - \\
\hline \multirow{5}{*}{$\mathrm{LC}$} & Grassland & 1.119 & 0.973 & 1.286 & - \\
\hline & Forest & 0.452 & 0.400 & 0.511 & - \\
\hline & Bare areas & 1.116 & 0.412 & 3.520 & - \\
\hline & Shrubs cover & 1.013 & 0.742 & 1.383 & - \\
\hline & Built-up land & 0.939 & 0.302 & 2.632 & - \\
\hline \multicolumn{2}{|c|}{ Prec. threshold exceedance } & 1.019 & 1.017 & 1.022 & 10 \\
\hline \multicolumn{2}{|c|}{ dDrainage } & 1.073 & 0.785 & 1.465 & 5000 \\
\hline \multicolumn{2}{|c|}{ Plan. curv. } & 0.733 & 0.700 & 0.768 & $2 \times 10^{8}$ \\
\hline \multicolumn{2}{|c|}{ Prof. curv. } & 1.035 & 1.020 & 1.050 & 0.001 \\
\hline \multicolumn{2}{|c|}{ East } & 1.004 & 0.997 & 1.012 & 0.1 \\
\hline \multicolumn{2}{|c|}{ North } & 1.006 & 0.999 & 1.013 & 0.1 \\
\hline
\end{tabular}

Table 5: Odds ratios (OR) for the different predictors, derived from the logistic regression (LR) model, together with their lower and upper bounds in the $95 \%$ confidence interval. The ORs of the dummy variables are referenced to cropland for LC, and to the Kivu formations for lithostratigraphy. 


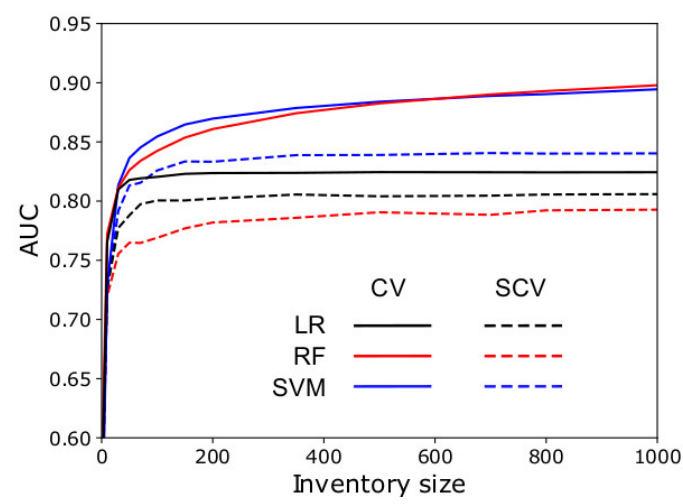

Figure 7: Impact of the size of the training data set on the accuracy and AUC for the three LSS modelling approaches: the logistic regression (LR), random forests $(\mathrm{RF})$ and the support vector machine (SVM).

We used an accurate PGA and lithostratigraphy map, constructed specifically for the WEAR. However, when our models were used with global (open) datasets, there was very little difference in terms of predictive power. In general, these datasets had an impact of less than $\pm 2 \%$ on the accuracy and AUC of the regional model. Hence, it seems there is only a limited added value of the regional datasets. Only for RF a decrease by more than $4 \%$ is observed when the global variables are used. Hence, it seems there is only a limited added value in using regional, accurate datasets for the covariates (Table 6).

\subsection{Comparing regional and continental/global LSS models}

The quantitative analysis of the three regional LLS models did not advocate for an optimal model choice: first of all, SVM stood out in terms of predictive power, displaying high AUC values for CV and SCV. Second, LR yielded the most robust results, but its predictive power was outperformed or at least matched by the two machine learning algorithms. Third, RF had the most optimal prediction rate curve (Fig. 8a). In such a case, the combination of LSS can provide optimal susceptibility assessments. We therefore combined the three resulting LLS maps (LR, RF, and SVM) in a new model using logistic regres- 


\begin{tabular}{|c|cc|cc|}
\hline Model & \multicolumn{2}{|c|}{ CV } & \multicolumn{2}{c|}{ SCV } \\
\hline LR & 83.2 & $\uparrow+0.7$ & 80.3 & $\downarrow-0.3$ \\
\hline RF & 92.1 & $\downarrow-0.7$ & 74.6 & $\downarrow-4.3$ \\
\hline SVM & 89.1 & $\downarrow-2.5$ & 83.4 & $\downarrow-0.9$ \\
\hline
\end{tabular}

Table 6: Results (\%) for the AUC of the logistic regression (LR), random forest (RF) and support vector machine (SVM) models trained with the global lithology and PGA datasets, calculated with 10-fold cross-validation (CV) and spatial cross-validation (SCV). The difference in quality with the original models (Table 3) is also indicated.

sion (Rossi et al. 2010a). The combined model scored significantly higher than each of the original three models, with AUC values of $92.4 \%$ and $91.6 \%$, for CV and SCV, respectively. All three original models had a statistically significant contribution $(p<0001)$, indicating they all added relevant information to the combined model. Therefore, we used this combined model for comparison with the global/continental LSS models in the study area (Section 3.6).

550

The models of Stanley \& Kirschbaum (2017) and Broeckx et al. (2018) have a similar discriminatory ability, but were clearly outperformed by the combined regional LSS model (Table 7). In the case of the latter model, more than $50 \%$ of the observed landslides fell within the highest LSS class, i.e. within the $10 \%$ pixels with the highest predicted LSS (Fig. 8b). As expected, the LSS classes assigned by the regional model were more accurate.

The spatial patterns produced by the three standardised models show similarities in terms of LSS class distribution (Fig. 9). The mountain ranges at the shores of both Lake Kivu and Lake Tanganyika (A) are highlighted as very prone to landsliding, with the western shores more susceptible than the eastern ones. The floodplain of the Ruzizi river (B) has, as expected, a low susceptibility, as has the eastern part of the study area $(\mathbf{C})$. In all three LSS models, the Virunga mountains north of Goma are highlighted as landslide-prone $(\mathbf{D})$, though the Nyiragongo and Nyamulagira volcanoes (E) are known for their slope stability, 


\begin{tabular}{|c|c|}
\hline Model & AUC \\
\hline Regional model & 92.4 \\
\hline Stanley \& Kirschbaum (2017) & 74.1 \\
\hline Broeckx et al. (2018) & 74.8 \\
\hline
\end{tabular}

Table 7: Discriminatory power of the regional model (i.e. the three models combined through LR) and two global/continental models, expressed as the AUC.
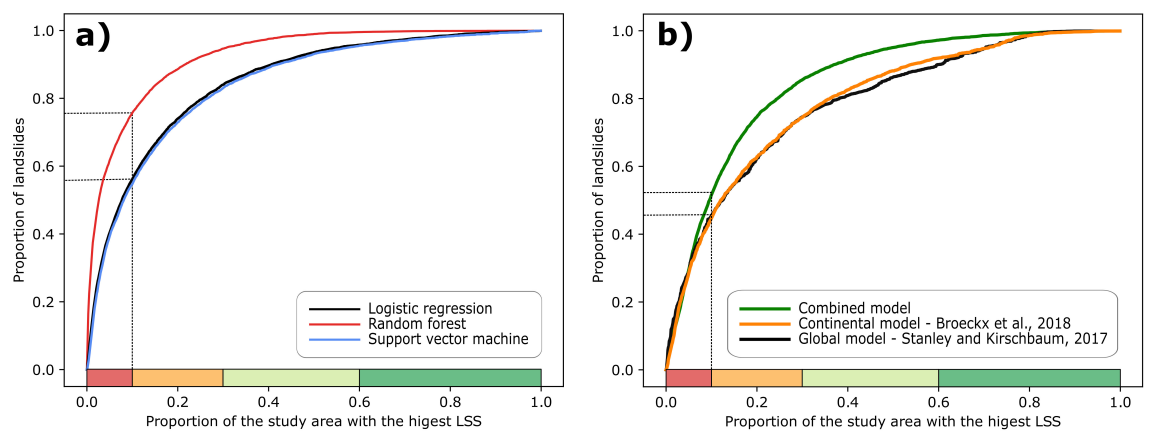

Figure 8: Prediction rates for a) the regional models and b) for the combined, continental, and global models. The prediction rate shows the proportion of landslides in function of the proportion of the study area with the highest LSS prediction. The different LSS classes are displayed on the x-axis.

as they recently erupted and the basalt is barely weathered. For Idjwi Island $(\mathbf{F})$, the three models highlight the difference between the highly susceptible east coast and the remainder of the island. This susceptibility pattern seems to reflect well the distribution of landslides on the island.

Despite the overall similarity, differences are observed in the northwestern part of the WEAR $(\mathbf{G})$, representing a significant part of the study area (Fig. 10. This area is indicated as very stable by the regional model, while the global models predict an intermediate to high LSS. The regional model matches field reality, as no landslides were inventoried for this area. 

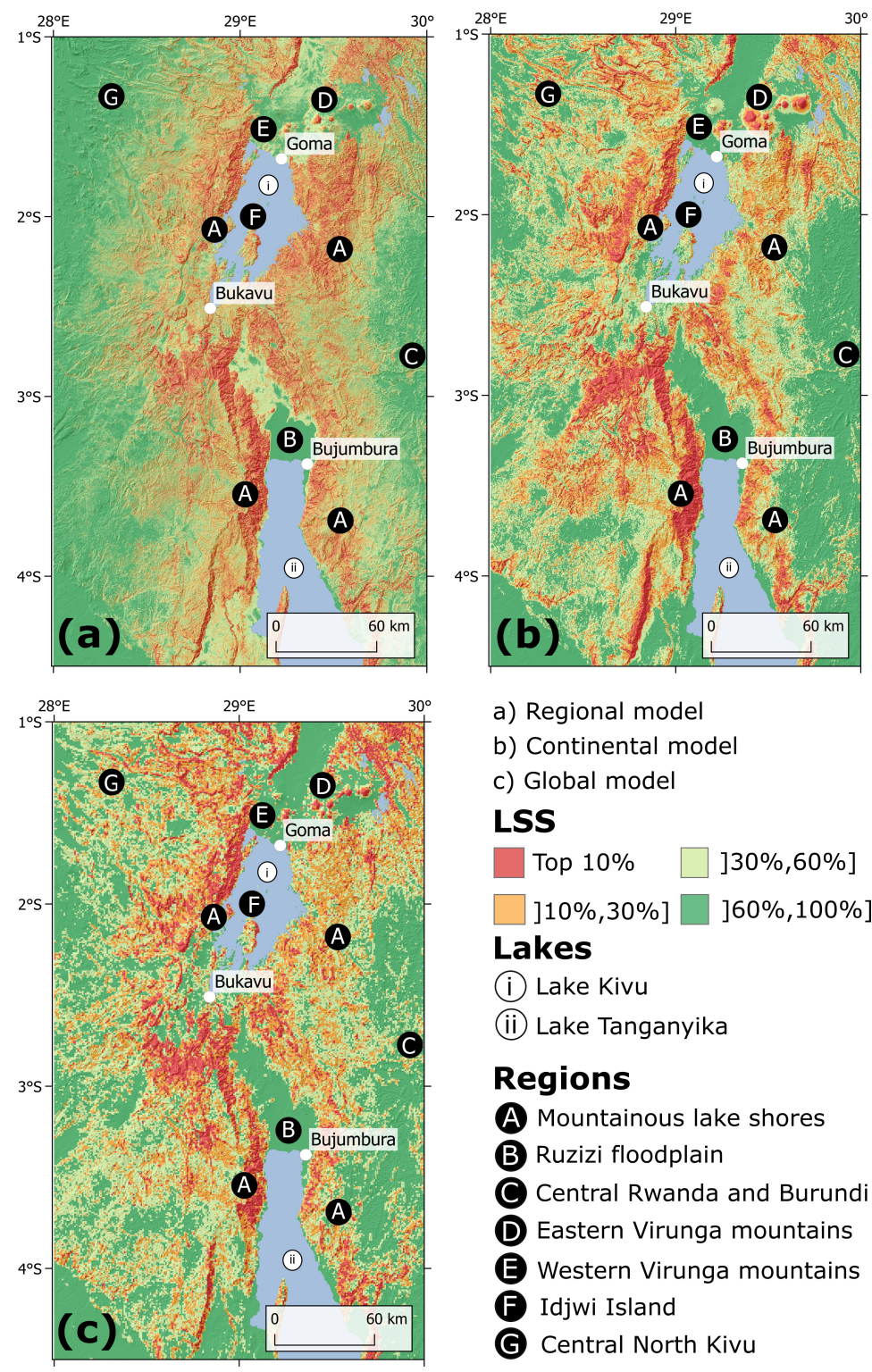
a) Regional model
b) Continental model
c) Global model

\section{LSS}
Top $10 \%$
$\square] 30 \%, 60 \%]$
]10\%,30\%]
]60\%,100\%]

\section{Lakes}

(i) Lake Kivu

(ii) Lake Tanganyika

\section{Regions}

A Mountainous lake shores

B Ruzizi floodplain

C Central Rwanda and Burundi

D Eastern Virunga mountains

E Western Virunga mountains

F Idjwi Island

G Central North Kivu

Figure 9: Standardised LSS for regional and global models: (a) the regional random forests model, (b) the continental model of Broeckx et al. (2018), and (c) the global model of Stanley \& Kirschbaum (2017). 


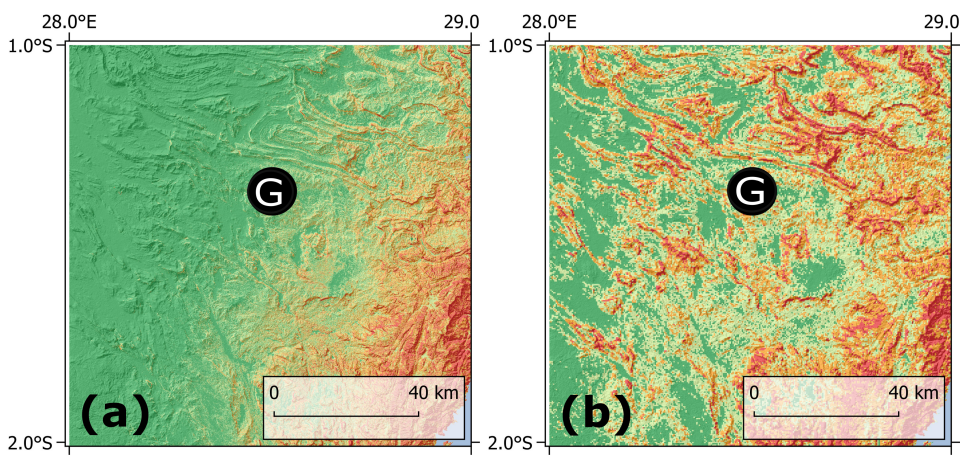
a) Regional model
b) Continental model
c) Global model

\section{LSS}

Top $10 \%$

] $10 \%, 30 \%$ ]

] $30 \%, 60 \%]$

]60\%,100\%]

G Central North Kivu
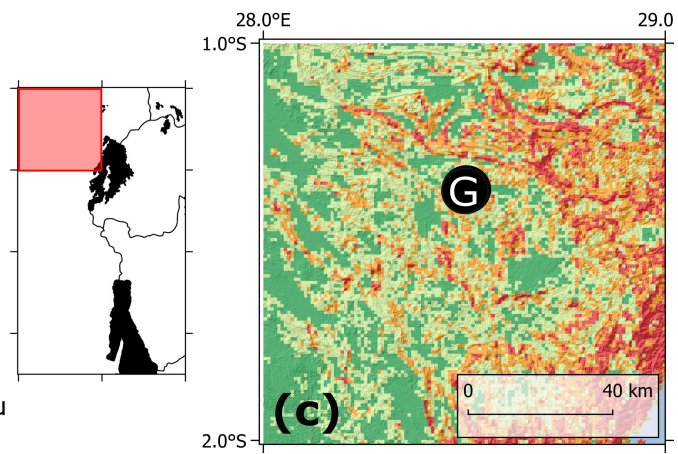

Figure 10: A highlighted region of the study area, showing the large differences in LSS between the regional model (a) and continental (b) and global (c) models (Broeckx et al. 2018; Stanley \& Kirschbaum, 2017). 
Our findings show that, within our study area where data scarcity is a challenge, the quality of the regional models is controlled by the size of landslide inventory, rather than the availability of accurate regionally constructed PGA and lithostratigraphy (Section 3.5) or the choice of the modelling technique (Section 3.3. It is reasonable to assume that this hypothesis is valid at least within regions of comparable environmental settings (a mountainous, tropical area), and for models that use similar spatial covariates. Indeed, this finding cannot be generalized to every region or every application. Henriques et al. (2015), for example, found that substituting the available geological map with a more detailed regionally constructed one did significantly improve the discriminatory power of their LSS model in Portugal.

However, our analysis does suggest that calibration with local landslide data is, in any case, very important to maximize the accuracy of predictive LSS maps. This is, as such, not surprising. It may indeed be assumed that the variables driving the initiation of landslides (such as slope) are, to a large extent universal. Nevertheless, their precise role will depend on local conditions. For example, the role of tree roots may depend strongly on the type of trees and the soil conditions which control rooting density and depth but also on the hydrological regime of the area which will control to what extent these roots change the soil moisture status. Similarly, the role of planar curvature may be more important in areas with an impermeable substrate (so that water is concentrated in concavities by throughflow) in comparison to areas with a highly permeable substrate where most water will infiltrate vertically, regardless of topographical variations.

Our applied methodology can be used by researchers to determine whether their landslide inventory is sufficiently large, or whether they should make efforts to increase the database size up to the point that further increasing it does not longer significantly impact the performance. At present, we do not have a theoretical basis to identify the optimal inventory size. Developing such a framework might be useful to provide other researchers with a sound basis for determining the necessary sample size for a specific region. It is not only important, however, that the sample is sufficiently large, it should also be unbiased. Recent shallow 
landslides have a distinct spectral signature and are highly visible, while present deep slowly moving landslides can only be detected through a thorough visual analysis of hillslope morphology. Evidently, both types of landslides need to be sampled accurately when they are present in the concerned area.

\section{Conclusions}

Although global and continental LSS models have their value for identifying areas with high susceptibility, they should only be applied on the scale for which they were constructed: within the WEAR we showed that regional LSS models strongly outperform global and continental alternatives in terms of predictive power and geomorphologic plausibility. Furthermore, we showed that the strongest gains in regional model quality were not obtained by investing in more complex model architecture or by using more accurate geological and seismic data, but by compiling a detailed regional landslide inventory allowing for a good local calibration. The necessity of local calibration follows from the fact that regions differ in their hydrology, geology, and vegetation (among others). Consequently, the precise role of variables in landslide initiation also differs.

The impact analysis of database size on the model quality learned that no or little improvement was obtained for inventories with more than \pm 500 instances. Beyond this point, the gains in quality were considered marginal with a maximal increase of the AUC of $1 \%$ per 1000 additional landslides. We recommend for future LSS assessments that the inventory compilation is guided by two principles: 1) a similar search time should be invested in each part of the study area in order to ensure that the inventory is representative for the region, and 2) the number of landslides does not necessarily need to be as large as possible. An impact analysis, similar to the one in this paper, can be used to evaluate whether the current database size suffices, or whether additional landslides should be mapped.

The different modelling approaches we used yielded similar results in terms of model quality, and the LR and SVM models built with the more accurate 
PGA and lithostratigraphy covariates scored maximally $2.5 \%$ better than the models that solely relied on open, less accurate data. For RF, the difference in quality induced by the more accurate covariates was somewhat more substantial (4.3\%). Considering the effort necessary for the construction of these regional data layers, their added value in regional LSS modelling in the WEAR can be questioned: within this context of data scarcity, it is clearly more important to build a good calibration and validation dataset.

Thus, the recent availability of global and/or continental LSS models should not discourage the development of dedicated regional assessments. The latter models offer an insight into the spatial susceptibility pattern which cannot be reproduced by global/continental alternatives. The construction of a representative landslide inventory should lie at the root of these regional LSS assessments. To achieve the latter, the incremental gain in model performance with inventory size can be used to indicate whether the database is sufficiently large.

\section{Acknowledgements}

This study was supported by the Belgium Science Policy (BELSPO) through (1) the PAStECA project (BR/165/A3/PASTECA) entitled 'Historical Aerial

Photographs and Archives to Assess Environmental Changes in Central Africa' (http://pasteca.africamuseum.be/), (2) the RESIST project (SR/00/305) entitled 'Remote Sensing and In Situ Detection and Tracking of Geohazards' (http://resist.africamuseum.be/), (3) the GeoRisCA project (SD/RI/02A), entitled 'Geo-Risk in Central Africa: integrating multi-hazards and vulnerabil655 ity to support risk management' (http://georisca.africamuseum.be), and (4) the AfReSlide project (BR/121/A2/AfRESLIDE) entitled 'Landslides in Equatorial Africa: Identifying culturally, technically and economically feasible resilience strategies' (http://afreslide.africamuseum.be/).

Data Availability: Landslide susceptibility maps presented in this study and landslide data used for their construction can be requested by contacting the corresponding author. 


\section{References}

Aleotti, P. (2004). A warning system for rainfall-induced shallow failures. Engineering Geology, 73, 247-265. doi 10.1016/j.enggeo.2004.01.007.

Basnet, B., \& Vodacek, A. (2015). Tracking land use/land cover dynamics in cloud prone areas using moderate resolution satellite data: A case study in Central Africa. Remote Sensing, 7, 6683-6709. doi:10.3390/rs70606683.

Belsley, D. A., Kuh, E., \& Welsch, R. E. (2005). Regression Diagnostics. Hoboken, New Jersey: John Wiley \& Sons. doi 10.1002/0471725153.

Bradley, A. P. (1996). The use of the area under the ROC curve in the evaluation n of machine learning algorithms. Pattern Recognition, 30, 1145-1159. doi:10. 1016/S0031-3203(96) 00142-2.

Breiman, L. (2001). Random Forests. Machine Learning, 45, 5-32. doi 10. 1023/A : 1010933404324

Brenning, A. (2012). Landslides and Engineered Slopes: Protecting Society through Improved Understanding. chapter Improved spatial analysis and prediction of landslide susceptibility: Practical recommendations.. (pp. 789795). Banff., Alberta, Canada: Taylor and Francis.

Broeckx, J., Vanmarcke, M., Duchateau, R., \& Poesen, J. (2018). A data-based landslide susceptibility map of Africa. Earth-Science Reviews, 185, 102-121. doi:10.1016/j.earscirev.2018.05.002.

Bucci, F., Santangelo, M., Cardinali, M., Fiorucci, F., \& Guzzetti, F. (2016). Landslide distribution and size in response to Quaternary fault activity: the Peloritani Range, NE Sicily, Italy. Earth Surface Processes and Landforms, 41, 711-720. doi:10.1002/esp.3898.

Budimir, M. E. A., Atkinson, P. M., \& Lewis, H. G. (2015). A systematic review of landslide probability mapping using logistic regression. Landslides, 12, 419-436. doi $10.1007 / \mathrm{s} 10346-014-0550-5$. 
Burbank, D. W., Leland, J., Fielding, E., Anderson, R. S., Brozovic, N., Reid,

M. R., \& Duncan, C. (1996). Bedrock incision, rock uplift and treshold

hillslopes in the northwestern Himalayas. Nature, 379, 505-510. doi 10.1038/ $379505 \mathrm{a0}$

Carlini, M., Chelli, A., Vescovi, P., Artoni, A., Clemenzi, L., Tellini, C., \& Torelli, L. (2016). Tectonic control on the development and distribution of large landslides in the Northern Apennines (Italy). Geomorphology, 253, 425-437. doi:10.1016/j.geomorph.2015.10.028.

Casagli, N., Guzzetti, F., Jaboyedoff, M., Nadim, F., \& Petley, D. (2017). Understanding Disaster Risk: Hazard Related Risk Issues - Hydrological risk: Landslides. In K. Poljan\usek, M. Marín Ferrer, T. De Groeve, \& I. Clark (Eds.), Science for Disaster Risk Management 201\%: Knowing Better and Losing Less (pp. 209-238). Publications Office of the European Union. doi: $10.2788 / 842809$.

Catani, F., Lagomarsino, D., Segoni, S., \& Tofani, V. (2013). Landslide susceptibility estimation by random forests technique: sensitivity and scaling issues. Natural Hazards and Earth System Sciences, 13, 2815-2831. doi:10.5194/nhess-13-2815-2013.

Chang, K. T., Chiang, S. H., \& Hsu, M. L. (2007). Modeling typhoon and earthquake-induced landslides in a mountainous watershed using logistic re-

口 gression. Geomorphology, 89, 335-347. doi 10.1016/j.geomorph.2006.12. 011 .

Chi, M., Feng, R., \& Bruzzone, L. (2008). Classification of hyperspectral remotesensing data with primal SVM for small-sized training dataset problem. $A d$ vances in Space Research, 41, 1793-1799. doi:10.1016/j.asr.2008.02.012.

Chung, C.-J. F., \& Fabbri, A. G. (2003). Validation of Spatial Prediction Models 715 ․ for Landslide Hazard Mapping. Natural Hazards, 30, 451-472. doi 10.1023/ B:NHAZ.0000007172.62651.2b. 
Corominas, C., van Westen, C., Frattini, P., Cascini, L., Malet, J.-P., Fotopoulou, S., Catani, F., Van Den Eeckhaut, M., Mavrouli, O., Agliardi, F., Pitilakis, K., Winter, M. G., Pastor, M., Ferlisi, S., Tofani, V., Hervás, J., \& Smith, J. T. (2014). Recommendations for the quantitative analysis of landslide risk. Bulletin of Engineering Geology and the Environment, 73, 209-263. doi $10.1007 / \mathrm{s} 10064-013-0538-8$.

Delvaux, D., \& Barth, A. (2010). African stress pattern from formal inversion of 1. focal mechanism data. Tectonophysics, 482, 105-128. doi $10.1016 / \mathrm{j}$.tecto. 2009.05 .009

Delvaux, D., Mulumba, J.-L., Sebagenzi, M. N. S., Bondo, S. F., Kervyn, F., \& Havenith, H.-B. (2017). Seismic hazard assessment of the Kivu rift segment based on a new seismotectonic zonation model (western branch, East African

n Rift system). Journal of African Earth Sciences, 134, 831-855. doi 10.1016/ j.jafrearsci.2016.10.004.

Dewitte, O., Chung, C.-J., Cornet, Y., Daoudi, M., \& Demoulin, A. (2010). Combining spatial data in landslide reactivation susceptibility mapping: A likelihood ratio-based approach in W Belgium. Geomorphology, 122, 153166. doi:10.1016/j.geomorph.2010.06.010.

Dewitte, O., Chung, C.-J., \& Demoulin, A. (2006). Reactivation hazard mapping for ancient landslides in West Belgium. Natural Hazard and Earth System Sciences, 6, 653-662. doi 10.5194/nhess-6-653-2006.

Dille, A., Kervyn, F., Mugaruka Bibentyo, T., Delvaux, D., Ganza, G. B., Ilombe, G. M., Kalikone, C. B., Nakito, E. S., Moeyersons, J., Monsieurs, 740 E., Nzolang, C., Smets, B., Kervyn, M., \& Dewitte, O. (2019). Causes and triggers of deep seated hillslope instability in the tropics insights from a 60-year record of Ikoma landslide (DR Congo). Geomorphology, .

ESA (2016). ESA Climate Change Initiative - Land Cover project 2017. $20 \mathrm{~m}$ resolution. European Space Agency, Paris, France. 
Fawcett, T. (2006). An introduction to ROC analysis. Pattern Recognition Letters, 27, 861-874. doi $10.1016 / \mathrm{j}$.patrec.2005.10.010.

Florynski, I. (1998). Accuracy of local topographic variables derived from digital elevation models. International Journal of Geographical Information Science, 12, 47-61. doi $10.1080 / 136588198242003$

750 Froude, M. J., \& Petley, D. N. (2018). Global fatal landslide occurrence from 2004 to 2016. Natural Hazard and Earth System Sciences, 18, 2161-2181. doi $10.5194 /$ nhess-18-2161-2018.

Gallen, S. F., Clark, M. K., \& Godt, J. W. (2015). Coseismic landslides reveal near-surface rock strength in a high-relief, tectonically active setting. Geology, 43, 11-14. doi $10.1130 /$ G36080.1.

Giardini, D., Grunthal, G., Shedlock, K. M., \& Zhang, P. (1999). The GSHAP

1. global seismic hazard map. Annali di Geofisica, 42, 1225-1230. doi 10.1785/ gssrl.71.6.679

Gill, J. C., \& Malamud, B. D. (2017). Anthropogenic processes, natural hazards, and interactions in a multi-hazard framework. Earth-Science Reviews, 166, 246-269. doi:10.1016/j.earscirev.2017.01.002.

Goetz, J. N., Brenning, A., Petschko, H., \& Leopold, P. (2015). Evaluating machine learning and statistical prediction techniques for landslide suscepq tibility modeling. Computers and Geosciences, 81, 1-11. doi $10.1016 / \mathrm{j}$. cageo.2015.04.007.

Grayson, R. B., Blöschl, G., Western, A. W., \& McMahon, T. A. (2002). Advances in the use of observed spatial patterns of catchment hydrologi口 cal response. Advances in Water Resources, 25, 1313-1334. doi 10.1016/ S0309-1708(02) 00060-X.

770 Guzzetti, F., Reichenbach, P., Ardizzone, F., Cardinali, M., \& Galli, M. (2006). Estimating the quality of landslide susceptibility models. Geomorphology, 81, 166-184. doi:10.1016/j.geomorph.2006.04.007. 
Hartmann, J., \& Moosdorf, N. (2012). The new global lithological map database GLiM: a representation of rock properties at the Earth surface. Geochemistry, Geophysics, Geosystems, 13, 1-37. doi 10.1029/2012GC004370.

Hastie, T., Tibshirani, R., \& Friedman, J. (2009). Elements of Statistical Learning: Data Mining, Inference, and Prediction. Series in Statistics (2nd ed.). New York, NY: Springer.

Havenith, H. B., Strom, A., Torgoev, I., Torgoev, A., Lamair, L., Ischuk, A., \& Abdrakhmatov, K. (2015a). Tien Shan Geohazards Database: Earthquakes 口 and landslides. Geomorphology, 249, 16-31. URL: http://dx.doi.org/10. 1016/j.geomorph.2015.01.037 doi:10.1016/j.geomorph.2015.01.037.

Havenith, H. B., Torgoev, A., Schlögel, R., Braun, A., Torgoev, I., \& Ischuk, A. (2015b). Tien Shan Geohazards Database: Landslide susceptibility anal-

ysis. Geomorphology, 249, 32-43. URL: http://dx.doi.org/10.1016/j. geomorph.2015.03.019, doi $10.1016 / j \cdot$ geomorph.2015.03.019.

Henriques, C., Zêzere, J. L., \& Marques, F. (2015). The role of the lithological setting on the landslide pattern and distribution. Engineering Geology, 189, 17-31. doi $10.1016 /$ j .enggeo.2015.01.025

Hong, Y., Adler, R., \& Huffman, G. (2007). Use of satellite remote sensing data in the mapping of global landslide susceptibility. Natural Hazards, 43, 245-256. doi:10.1007/s11069-006-9104-z.

Hosmer, D. W., \& Lemeshow, S. (2000). Applied Logistic Regression. (2nd ed.). Hoboken, NJ: John Wiley \& Sons. doi:10.1002/0471722146.

Hsu, C.-W., Chang, C.-C., \& Lin, C.-J. (2016). A Practical Guide to Support Vector Classification. Technical Report Department of Computer Science, National Taiwan University Taipei, Taiwan.

Huang, C., Davis, L. S., \& Townshend, J. R. G. (2002). An assessment of support vector machines for land cover classification. International Journal of Remote Sensing, 23, 725-749. doi $10.1080 / 01431160110040323$. 
Huang, H.-P., Yang, K.-C., \& Lin, B.-W. (2013). Statistical evaluation of the effect of earthquake with other related factors on landslide susceptibility: using the watershed area of Shihmen reservoir in Taiwan as a case study. Environmental Earth Sciences, 69, 2151-2166. doi 10.1007/s12665-012-2044-x.

Igwe, O. (2015). The geotechnical characteristics of landslides on the sedimentary and metamorphic terrains of South-East Nigeria, West Africa. Geoenvironmental Disasters, 2, 1-14. doi 10.1186/s40677-014-0008-z

Jacobs, L., Dewitte, O., Poesen, J., Sekajugo, J., Nobile, A., Rossi, M., Thierry, W., \& Kervyn, M. (2018). Field-based landslide susceptibility assessment in a data-scarce environment: the populated areas of the Rwenzori Mountains. Natural Hazards and Earth System Sciences, 18, 105-124. doi:10.5194/nhess-18-105-2018.

Jacobs, L., Olivier, D., Poesen, J., Delvaux, D., Thierry, W., \& Kervyn, M. (2016). The Rwenzori Mountains, a landslide-prone region? Landslides, 13, 519-536. doi $10.1007 /$ s10346-015-0582-5.

Jakob, M. (2000). The Impacts of Logging on landslide activity at Clay口 oquot Sound, British Columbia. Catena, 38, 279-300. doi 10.1016/ S0341-8162(99) 00078-8.

Jung, Y. (2018). Multiple predicting K-fold cross-validation for model selection. 820 „ Journal of Nonparametric Statistics, 30, 197-215. doi 10.1080/10485252. 2017.1404598 .

Khazai, B., \& Sitar, N. (2004). Evaluation of factors controlling earthquakeinduced landslides caused by Chi-Chi earthquake and comparison with the a Northridge and Loma Prieta events. Engineering Geology, 71, 79-95. doi 10. 1016/S0013-7952(03) 00127-3.

Kleinbaum, D. G., \& Klein, M. (2011). Logistic Regression: A Self-Learning Text. Statistics for Biology and Health (3rd ed.). New York, NY: Springer. doi $10.1111 / j .1751-5823.2011 .00149 \_22 . x$. 
Korup, O., Densmore, A. L., \& Schlunger, F. (2010). The role of landslides 830 ㄱ in mountain range evolution. Geomorphology, 120, 77-90. doi $10.1016 / \mathrm{j}$. geomorph.2009.09.017.

Kubwimana, D., Ait Brahim, L., Bousta, M., Dewitte, O., Abdelouafi, A., \& Bahaj, T. (2018). Landslides susceptibility assessment using AHP method in Kanyosha watershed (Bujumbura-Burundi): Urbanisation and management impacts. MATEC Web of Conferences, 149, 02071. URL: https://

1. WwW.matec-conferences.org/10.1051/matecconf/201714902071. doi 10. 1051/matecconf/201714902071.

Laghmouch, M., Kalikone, C., Ilombe, G., Ganza, G., Delvaux, D., Safari, E., Bachinyaga, J., Wazi, N., Nzolang, C., Fernandez, M., Nimpagaritse, G.,

${ }_{840}$ Tack, L., Dewaele, S., \& Kervyn, F. (2018). Carte géologique du Kivu au 1/500 000. Tervuren, Belgium: Africamuseum, Bukavu, DRC: Université Officielle de Bukavu.

Larsen, I. J., \& Montgomery, D. R. (2012). Landslide erosion coupled to tectonics and river incision. Nature Geoscience, 5, 468-473. doi:10.1038/NGE01479

${ }_{845}$ Lin, L., Lin, Q., \& Wang, Y. (2017). Landslide susceptibility mapping on a global scale using the method of logistic regression. Natural Hazards and Earth System Sciences, 17, 1411-1427. doi:10.5194/nhess-17-1411-2017.

Linard, C., Gilbert, M., Snow, R. W., Noor, A. M., \& Tatem, A. J. (2012). Population distribution, settlement patterns and accessibility across Africa in 2010. PLoS ONE, 7, e31743. doi:10.1371/journal.pone.0031743

Ma, Y., \& Guo, G. (Eds.) (2014). Support Vector Machines Applications. ₫ Cham, Switzerland: Springer International Publishing AG. doi 10.1007/ 978-3-319-02300-7.

Maidment, R., Grimes, D., Allan, R., Tarnavsky, E., Stringer, M., Hewison, T., 855 Roebeling, R., \& Black, E. (2014). The 30-year TAMSAT African Rainfall 
Climatology and Time-series (TARCAT) Data Set. Journal of Geophysical Research: Atmospheres, 119, 10619-10644. doi:10.1002/2014JD021927.

Maidment, R. I., David Grimes, D., Emily Black, E., Elena Tarnavsky, E., Young, M., Greatrex, H., Allan, R. P., Stein, T., Nkonde, E., Senkunda, S., \& Alc'antara, E. M. U. (2017). A new, long-term daily satellite-based rainfall dataset for operational monitoring in Africa. Scientific Data, 4, 170063. doi:10.1038/sdata.2017.63.

Maki Mateso, J.-C., \& Dewitte, O. (2014). Towards an inventory of landslide processes and the elements at risk on the Rift flanks, West of Lake Kivu (DRC). Geo-Eco-Trop, 38, 137-154.

Malamud, B. D., Turcotte, D. L., Guzzetti, F., \& Reichenbach, P. (2004). Landslide inventories and their statistical properties. Earth Surface Processes and Landforms, 29, 687-711. doi:10.1002/esq.1064.

Marc, O., Hovius, N., Meunier, P., Uchida, T., \& Hayashi, S. (2015). Transient 870 „ changes of landslide rates after earthquakes. Geology, 43, 883-886. doi 10. 1130/G36961.1.

Marc, O., Meunier, P., \& Hovius, N. (2017). Prediction of the area affected by earthquake-induced landsliding based on seismological parameters.

口 Natural Hazard and Earth System Sciences, 17, 1159-1175. doi 10.5194/ nhess-17-1159-2017.

Michellier, C., Pigeon, P., Kervyn, F., \& Wolff, E. (2016). Contextualizing vulnerability assessment: a support to geo-risk management in central Africa. Natural Hazards, 82, S27-S42. doi:10.1007/s11069-016-2295-z.

Monsieurs, E., Jacobs, L., Michellier, C., Basimike, J., Bamulezi Ganza, G., Kervyn, F., Maki Mateso, J.-C., Mugaruka Bibentyo., T., Kalikone Buzera, C., Nahimana, L., Ndayisenga, A., Nkurunziza, P., Thiery, W., Demoulin, A., Kervyn, M., \& Dewitte, O. (2018). Landslide inventory for hazard assess- 
ment in a data- poor context: a regional-scale approach in a tropical African environment. Landslides, 15, 2195-2209. doi:10.1007/s10346-018-1008-y.

Monsieurs, E., Kirschbaum, D. B., Thiery, W., van Lipzig, N., Kervyn, M., Demoulin, A., Jacobs, L., Kervyn, F., \& Dewitte, O. (2017). Constraints on Landslide-Climate Research Imposed by the Reality of Fieldwork in Central Africa. In J. V. De Graff, \& A. Shakoor (Eds.), 3rd North American Symposium on Landslides: Landslides: Putting Experience, Knowledge, and Emerging Technologies into Practice. Association of Environmental $\& 3$ Engineering Geologists (AEG) (pp. 158-168).

Montgomery, D. R., Schmidt, K. M., Greenberg, H. M., \& Dietrich, W. E. (2000). Forest clearing and regional landsliding. Geology, 28, 311-314.

Mugaruka Bibentyo., T., Kulimushi, M. S., Muhindo, S. W., \& Dewitte, O. (2017). Anatomy of Nyakavogo landslide (Bukavu, DR Congo): interplay between natural and anthropogenic factors. Geo-Eco-Trop, 41, 249-261.

Nadim, F., Kjekstad, O., Peduzzi, P., Herold, C., \& Jaedicke, C. (2006).

口 Global landslide and avalanche hotspots. Landslides, 3, 159-173. doi 10. 1007/s10346-006-0036-1.

${ }_{500}$ Nibigira, L., Havenith, H.-B., Archambeau, P., \& Dewals, B. (2018). Formation, breaching and flood consequences of a landslide dam. Natural Hazards and Earth System Science, 18, 1867-1890. doi 10.5194/nhess-18-1867-2018.

Nobile, A., Dille, A., Monsieurs, E., Basimike, J., Mugaruka Bibentyo., T., D'Oreye, N., Kervyn, F., \& Dewitte, O. (2018). Multi-Temporal DInSAR to Characterise Landslide Ground Deformations in a Tropical Urban Environment: Focus on Bukavu (DR Congo). Remote Sensing, 10, 626. doi: $10.3390 /$ rs10040626.

Oth, A., Barrière, J., dOreye, N., Mavonga, G., Subira, J., Mashagiro, N., Kadufu, B., Fiama, S., Celli, G., Bigirande, J. d. D., Ntenge, A. J., Habonimana, L., Bakundukize, C., \& Kervyn, F. (2017). KivuSNet: The First Dense 
Broadband Seismic Network for the Kivu Rift Region (Western Branch of n East African Rift). Seismological Research Letters, 88, 49-60. URL: https:

a //pubs.geoscienceworld.org/srl/article/88/1/49-60/314328 doi 10 . $1785 / 0220160147$.

915 Pasuto, A., \& Silvano, S. (1998). Rainfall as a triggering factor of shallow mass movements: A case study in the Dolomites, Italy. Environmental Geology, 35, 184-189. doi $10.1007 / \mathrm{s} 002540050304$.

Peng, L., Niu, R., Huang, B., Wu, X., Zhao, Y., \& Ye, R. (2014). Landslide susceptibility mapping based on rough set theory and support vector machines: A case of the Three Gorges area, China. Geomorphology, 204, 287-

q 301. URL: http://dx.doi.org/10.1016/j.geomorph.2013.08.013 doi 10. 1016/j.geomorph.2013.08.013

Petschko, H., Bell, R., \& Glade, T. (2014a). Relative Age Estimation at Landslide Mapping on LiDAR Derivatives: Revealing the Applicability of Land Cover Data in Statistical Susceptibility Modelling. In K. Sassa, P. Canuti, \& Y. Yin (Eds.), Landslide Science for a Safer Geoenvironment chapter Relative A. (pp. 337-343). Cham: Springer International Publishing. URL: http://link.springer.com/10.1007/978-3-319-05050-8_53 doi:10.1007/978-3-319-05050-8_53.

${ }_{930}$ Petschko, H., Bell, R., \& Glade, T. (2016). Effectiveness of visually analyzing LiDAR DTM derivatives for earth and debris slide inventory mapping for

a statistical susceptibility modeling. Landslides, 13, 857-872. doi 10.1007/ s10346-015-0622-1.

Petschko, H., Brenning, A., Bell, R., Goetz, J., \& Glade, T. (2014b). Assessing the quality of landslide susceptibility maps - case study Lower Aus-

口 tria. Natural Hazards and Earth System Sciences, 14, 95-118. doi 10.5194/ nhess-14-95-2014

Pouclet, A., Bellon, H., \& Bram, K. (2016). The Cenozoic volcanism in the Kivu rift: Assessment of the tectonic setting, geochemistry, and geochronology 
of the volcanic activity in the South-Kivu and Virunga regions. Journal of

ㅁ African Earth Sciences, 121, 219-246. doi 10.1016/j.jafrearsci.2016.05. 026 .

Reichenbach, P., Rossi, M., Malamud, B. D., Mihir, M., \& Guzzetti, F. (2018). A review of statistically-based landslide susceptibility models. Earth-Science

945 Reviews, 180, 60-91. doi 10.1016/j.earscirev.2018.03.001.

Roback, K., Clark, M. K., West, A. J., Zekkos, D., Li, G., Gallen, S. F., Chamlagain, D., \& Godt, J. W. (2018). The size, distribution, and mobility of landslides caused by the 2015 Mw7.8 Gorkha earthquake, Nepal. Geomorphology, 301, 121-138. doi 10.1016/j.geomorph.2017.01.030.

${ }_{950}$ Rodriguez C. E., M. C. S., \& Belz, J. E. (2006). A Global Assessment of the SRTM Performance. Photogrammetric Engineering and Remote Sensing, 72, 249-260. doi:10.14358/PERS.72.3.249.

Roering, J. J., Schmidt, K. M., Stock, J. D., Dietrich, W. E., \& Montgomery, M. R. (2003). Shallow landsliding, root reinforcement, and the spatial distribution of trees in the Oregon Coast Range. Canadian Geotechnical Journal, 40, 237-253. doi $10.1139 /$ t02-113

Ross, K. A., Smets, B., De Batist, M., Hilbe, M., Schmid, M., \& Anselmetti, F. S. (2014). Lake-level rise in the late Pleistocene and active subaquatic volcanism since the Holocene in Lake Kivu, East African Rift. Geomorphol-

960 q ogy, 221, 274-285. URL: http://dx.doi.org/10.1016/j.geomorph.2014. 05.010, doi $10.1016 / \mathrm{j} \cdot$ geomorph.2014.05.010

Rossi, M., Guzzetti, F., Reichenbach, P., Mondini, A. C., \& Peruccacci, S. (2010a). Optimal landslide susceptibility zonation based on multiple fore-

口 casts. Geomorphology, 114, 129-142. URL: http://dx.doi.org/10.1016/ j.geomorph.2009.06.020 doi 10.1016/j.geomorph.2009.06.020

Rossi, M., Luciani, S., Valigi, D., Kirschbaum, D., Brunetti, M. T., Peruccacci, S., \& Guzzetti, F. (2017). Statistical approaches for the definition of landslide 
rainfall thresholds and their uncertainty using rain gauge and satellite data. Geomorphology, 285, 16-27. doi 10.1016/j.geomorph.2017.02.001.

Schmidt, K. M., \& Montgomery, D. R. (1995). Limits to relief. Science, 270, 617-620. doi $10.1126 /$ science.270.5236.617.

Sidle, R. C., \& Bogaard, T. A. (2016). Dynamic earth system and ecological controls of rainfall-initiated landslides. Earth-Science Reviews, 159, 275-291. doi $10.1016 / \mathrm{j}$. earscirev.2016.05.013.

Sidle, R. C., \& Ochiai, H. (2006). Landslides: Processes, Prediction and Land Use. American geophysical union. doi 10.1029/WM018.

Smets, B., Delvaux, D., \& Kervyn, M. (2016). The role of inherited crustal structures and magmatism in the development of rift segments : Insights from the Kivu basin , western branch of the East African Rift. Tectonophysics, 683, 62-76. doi:10.1016/j.tecto.2016.06.022.

Stanley, T., \& Kirschbaum, D. B. (2017). A heuristic approach to global landa slide susceptibility mapping. Natural Hazards, 87, 145-164. doi 10.1007/ s11069-017-2757-y. 
(2016). Exploring discrepancies between quantitative validation results and the geomorphic plausibility of statistical landslide susceptibility maps. Geomorphology, 262, 8-23. doi:10.1016/j.geomorph.2016.03.015

Stevens, F. R., Gaughan, A. E., Linard, C., \& Tatem, A. J. (2015). Disaggregating Census Data for Population Mapping Using Random Forests with Remotely-Sensed and Ancillary Data. PLoS ONE, 10, e0107042. doi:10.1371/journal.pone.0107042.

Tarnavsky, E., Grimes, D., Maidment, R., Black, E., Allan, R., Stringer, M., Chadwick, R., \& Kayitakire, F. (2014). Extension of the TAMSAT Satellitebased Rainfall Monitoring over Africa and from 1983 to present. Journal of Applied Meteorology and Climatology, 53, 2805-2822. doi 10.1175/ JAMC-D-14-0016.1.

Ugai, K., Yagi, H., \& Wakai, A. (Eds.) (2012). Earthquake-Induced Landslides: Proceedings of the International Symposium on Earthquake-Induced 1010 ¿ Landslides, Kiryu, Japan, 2012. New York: Springer. doi 10.1007/ 978-3-642-32238-9.

USGS (2006a). Shuttle Radar Topography Mission, Global Land Cover Facility. 1 Arc-Second. University of Maryland, College Park, Maryland.

USGS (2006b). Shuttle Radar Topography Mission, Global Land Cover Facility. 3 Arc-Second. University of Maryland, College Park, Maryland.

Van Den Eeckhaut, M., Poesen, J., Govers, G., Verstraeten, G., \& Demoulin, A. (2007). Characteristics of the size distribution of recent and historical landslides in a populated hilly region. Earth and Planetary Science Letters, 256, 599-603. doi:10.1016/j.epsl.2007.01.040.

Vanmaercke, M., Ardizzone, A., Rossi, M., \& Guzzetti, F. (2017). Exploring the effects of seismicity on landslides and catchment sediment yield: An Italian 
口 case study. Geomorphology, 278, 171-183. doi:10.1016/j.geomorph.2016. 11.010 .

Vapnik, V. N. (1995). The Nature of Statistical Learning Theory. New York, NY: Springer.

Villeneuve, M. (1976). Mise en évidence d'une discordance angulaire majeur dans les terrains précambriens au nord du flanc oriental du "synclinal de l'Itombwe" (région du Kivu, Zaïre). Comptes Rendus de l'Académie des Sciences, 282, 1709-1712.

Walker, L. R., \& Shiels, A. B. (2013). Landslide Ecology. Cambridge: Cambridge University Press. doi:10.1017/CB09780511978685.

van Westen, C. J., van Asch, T. W. J., \& Soeters, R. (2006). Landslide hazard and risk zonation - why is it still so difficult? Bulletin of Engineering Geology and the Environment, 65, 167-184. doi:10.1007/s10064-005-0023-0.

Wilson, R. C., \& Keefer, D. K. (1985). Predicting areal limits of earthquakeinduced landsliding, in: Evaluating earthquake hazards in the Los Angeles Region: an Earth science perspective. Technical Report 1360, pp. 317-345 US Geological Survey.

WorldPop (2017). Alpha version 2010 and 2015 estimates of numbers of people per grid square, with national totals adjusted to match UN population division estimates (http://esa.un.org/wpp/) and remaining unadjusted. 3 Arc-Second resolution. University of Southampton, Sout.

Zhou, Q., \& Liu, X. (2008). Assessing Uncertainties in Derived Slope and Aspect from a Grid DEM. In Q. Zhou, \& G. Tang (Eds.), Advances in 1045 Digital Terrain Analysis chapter Assessing. (pp. 279-306). New York, NY: Springer. doi:10.1007/978-3-540-77800-4 


\section{Supplementary}
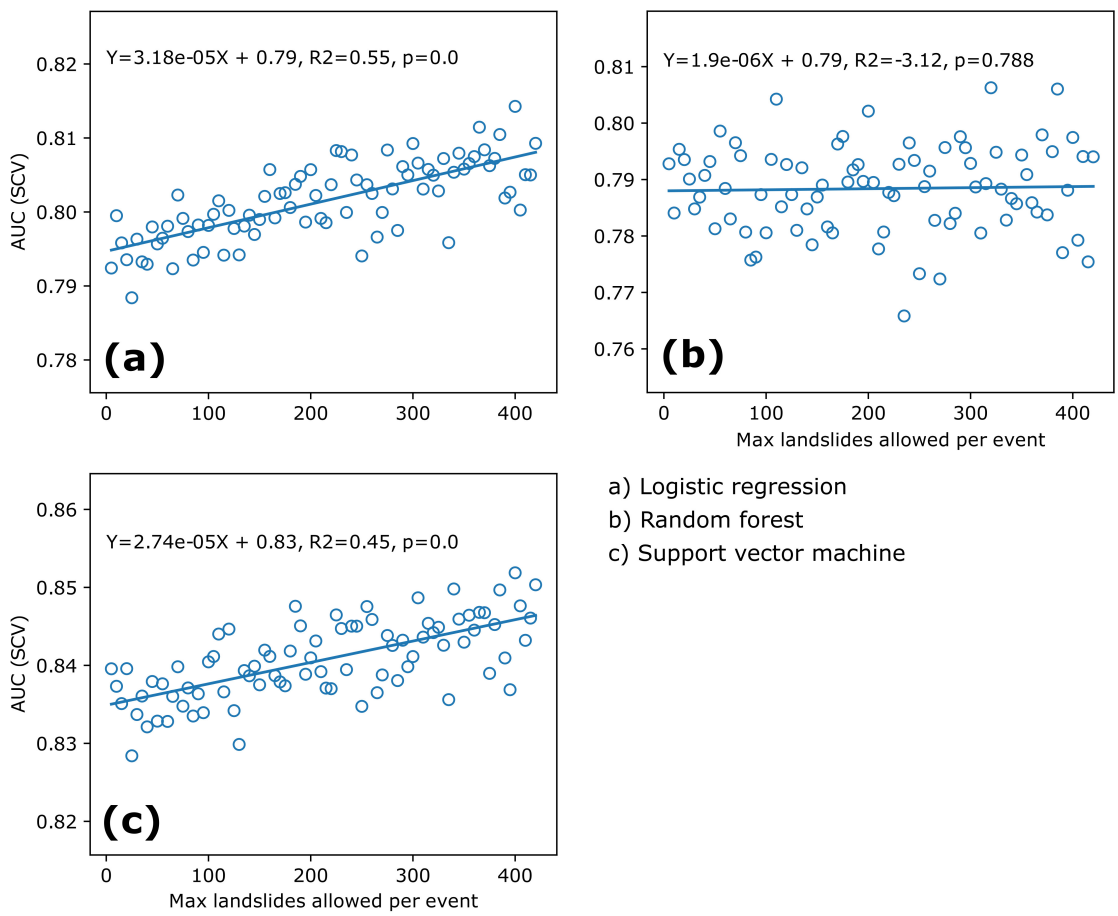

a) Logistic regression

b) Random forest

c) Support vector machine

Figure S1: The impact of limiting the maximum number of landslides allowed per event on the quality of the different LSS models. The model quality was expressed as the AUC, calculated with spatial cross-validation in order to assess how the extrapolation ability of the models was affected. Increasing the impact of events (i.e. increasing the number of landslides allowed per event) seemed to increase the model quality marginally for LR and SVM, while there is no effect for random forests. Hence, within our analyses, we decided to include all the landslides for every event. 

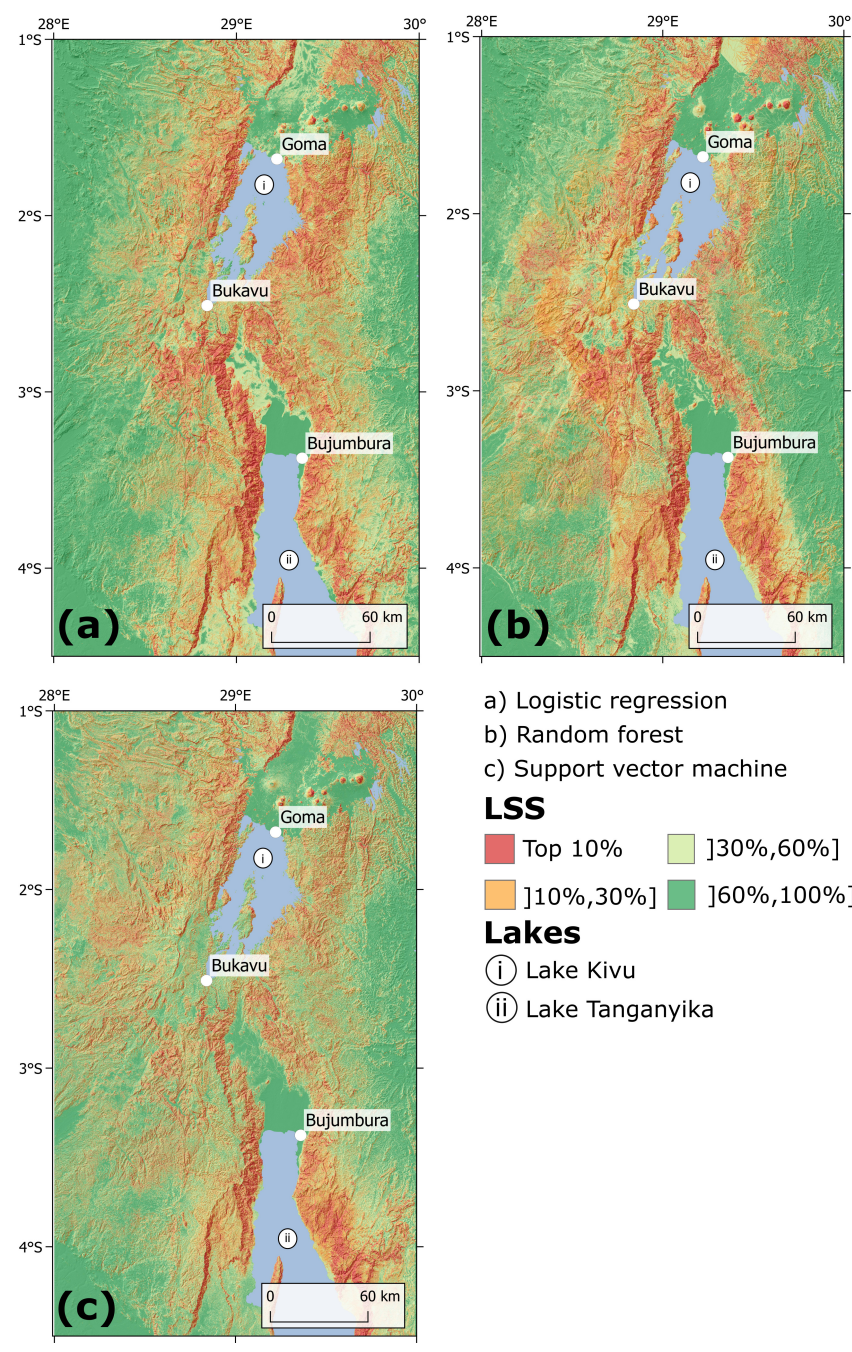

a) Logistic regression

b) Random forest

c) Support vector machine

LSS

Top 10\% $\square$ ]30\%,60\%]

]10\%,30\%] [ ]60\%,100\%]

Lakes

(i) Lake Kivu

(ii) Lake Tanganyika

Figure S2: LSS maps created with (a) logistic regression, (b) random forests, and (c) support vector machines and only 500 randomly sampled landslides were used to train each model. No significant changes in the LSS pattern was observed between these maps and their counterparts that were trained with the entire database. 